No. 19.

(Published August 1926)

\title{
On the Distribution of Shearing Stresses in Beams of Certain Cross-Sections.
}

\author{
$\mathrm{By}$ \\ Tuneo INOKuTY, Kôsakusi, \\ Member of the Institute.
}

\begin{abstract}
.
In Part $I$, the shearing stresses in beams are found from Saint-Venant's fexure functions for two forms of cross-sections, namely, (r) a section bounded by two confocal ellipses, and (2) a sector of a circle. In virtue of the results obtained, a simple practical formula for the shearing stress in a thin hollow elliptic cylindrical beam is introduced, and it is proved that an intense shearing stress is induced at the corner of a sharp re-entrant and at the end of a crack in the cross-section.

Part II is the description of the experiments which are undertaken for the confirmation of the stress-concentration obtained analytically in Part I.

Saint-Venant's flexure functions for the above sections are deduced in Appendix $I$, and the shearing stresses in a circular cylindrical beam and in a hollow circular cylindrical beam are given in Appendix II.
\end{abstract}

\section{Introduction.}

In the first part of this paper, the distribution of shearing stresses in a beam subjected to a shearing force is mathematically found by Saint-Venant's flexure function for certain special forms 
Corrections.

\begin{tabular}{|c|c|c|c|}
\hline Page & I.ine & Misprint & Correction \\
\hline 157 & 3 & $-\left(\frac{3}{16}-\frac{1}{8} \sigma\right)$ & $-\left(\frac{1}{16}-\frac{1}{8} \sigma\right)$ \\
177 & Table 3 & Elo gation & $\frac{\text { Elongation }}{\text { fixed }}$ \\
193 & 21 & fix d & Surface \\
P1. 8 & Fig. 11 & Surfae & . \\
\hline
\end{tabular}


of cross-section. One of the remarkable results of this theoretical study is the fact that an intense shearing stress is induced at the corner of a sharp re-entrant in the cross-section of a beam. The problems relating to the stress-concentrations at discontinuities have been studied by many investigators, namely, Professor Suyehiro, ${ }^{(1)}$ Professor Inglis, (3) Dr. Bruhn, (3) Professor Coker, ${ }^{(4)}$ and Griffith and Taylor. ${ }^{(\bar{j})}$ So far as the author is aware, however, the stress-concentration as dealt with here has not yet been attempted mathematically, although a similar investigation was made experimentally by Griffith and Taylor(6) on a " $\mathrm{T}$ " beam by the soap-film method. For the confirmation of the result obtained analytically by the author, he undertook also some experiments, which are described in the last part of the paper.

\section{Part I. Mathematical Solutions.}

\section{A Hollow Cylindrical Beam of an Elliptic Section.}

T.et us take a hollow cylindrical beam, the cross-section of which is of a form bounded by two confocal ellipses. Taking the longitudinal axis of the beam to be horizontal and one end of which

(1) Prof. Suyehiro, "The Distribution of Stress in Plates having Discontinuities and some Problems connected with it." Jour. Soc. Nav. Arch., Tokyô, Vol. X, and Engineering, Sept. i, rgir.

(2) Prof. Inglis, "Stresses in a Plat" due to the Presencz of Cracks and Sharp Corners." Trans. Inst. Nav. Arch., 1913, Part I.

(3) Dr. Bruhn, "The Stresses at the Discontinuities in a Ship's Structure." Trans. Inst. Nav. Arch., 1 S $99 .^{2}$

(4) Prof. Coker and Scoble, "The Distribution of Stress due to a Rivet in a Plate." Trans. Inst. Nav. Arch., I9I3, Part I.

(5) Griffith and Taylor, "The Use of Soap Films in Solving Torsion Problems," and "The Applicaion of Soap Films to the Determination of the Torsion and Flexure of IIollow Shafts." Report of Advisory Committee for Aeronautics, 1917-18.

(6) Griffith and Taylor, "The Problem of Flexure and its Solution ly the SoafFilm Method." Report of Advisory Committee for Aeronautics, 1917-IS. 
to be fixed, we suppose that forces are applied to the cross-section at the free end in such a way as to be equivalent to a vertical load $W$ acting on a line through the centroid of the section. We take the origin at the fixed end, and the axis of $z$ along the longitudinal axis through the centroid of the section. Further we take the major axis of the ellipse as the axis of $x$, and the minor axis as the axis of $y$ as shown in Fig. $\mathrm{r}$.

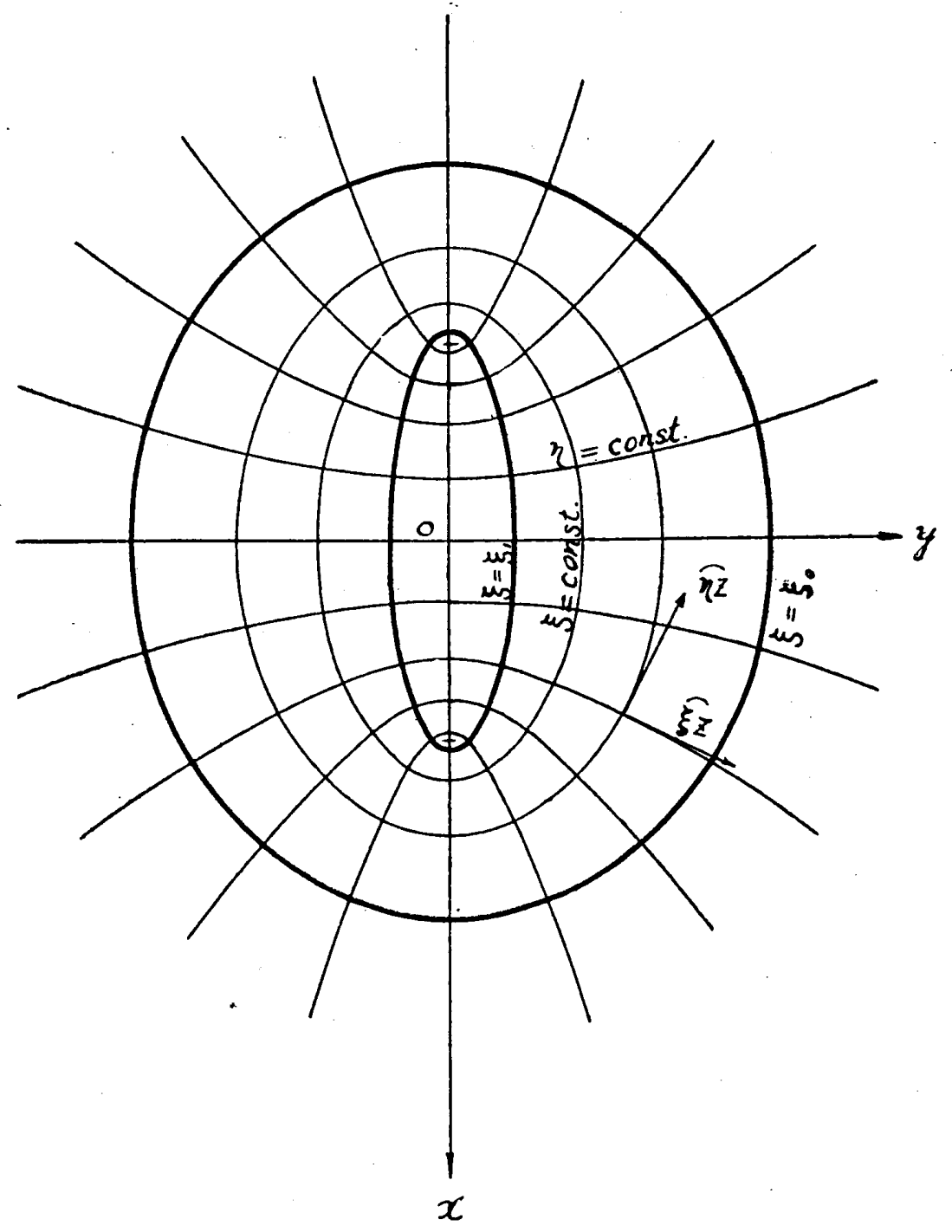

rig. I. 
We introduce the curvilinear orthogonal co-ordinates $\xi, \eta$ in the plane $x y$, which are conjugate functions given by the equation

$$
x+i y=c \cosh (\xi+i \eta) \text {. }
$$

Then we have.

$$
x=c \cosh \xi \cos \eta, \quad y=c \sinh \xi \sin \eta
$$

The curves $\xi=$ const. are confocal ellipses

$$
\frac{x^{2}}{c^{2} \cosh ^{2} \xi}+\frac{y^{2}}{c^{2} \sinh ^{2} \xi}=\mathrm{I}
$$

having the common foci $( \pm c, 0)$. The curves $\eta=$ const. are hyperbolas

$$
\frac{x^{2}}{c^{2} \cos ^{2} \eta}-\frac{y^{2}}{c^{2} \sin ^{2} \eta}=\mathrm{I}
$$

and these two systems of curves cut one another at right angles. Take $\xi_{\theta}$ and $\xi_{1}$ to be the values of $\xi$ which correspond with the outer and inner boundaries of the cross-section of the beam.

(a) When the major axis is wertical. - Take the axis of $x$ vertically downwards. The flexure function $\chi$ for this section is $\chi=c^{3} \cos \eta\left[\left(\frac{1}{4}-\frac{1}{8} \sigma\right) \cosh \xi-\left(\frac{3}{4}+\frac{1}{2} \sigma\right)\left\{\cosh \xi_{0} \cosh \xi_{1} \cosh \left(\xi_{0}+\xi_{1}\right) \cosh \xi\right.\right.$ $\left.\left.-\sinh \xi_{0} \sinh \xi_{1} \sinh \left(\xi_{0}+\xi_{1}\right) \sinh \xi\right\}\right]$

$$
\begin{aligned}
& +c^{3} \cos 3 \eta\left[\frac{1}{16} \cosh 3 \xi\right. \\
& \left.-\left(\frac{1}{16}-\frac{1}{8} \sigma\right) \frac{\sinh \xi_{0} \cosh 3\left(\xi-\xi_{1}\right)-\sinh \xi_{1} \cosh 3\left(\xi_{0}-\xi\right)}{3 \sinh 3\left(\xi_{0}-\xi_{1}\right)}\right],
\end{aligned}
$$

where $\sigma$ is Poisson's ratio. For finding this function, see Appendix I.

If the load $W$ is directed parallel to the axis of $x$, the shearing stress components on the cross-section when the section is sym- 
metrical about the vertical axis are given by

$$
\left.\begin{array}{l}
X_{z}=-\frac{W}{2(\mathrm{I}+\sigma) I}\left\{\frac{\partial \chi}{\partial x}+\frac{1}{2} \sigma x^{2}+\left(\mathrm{I}-\frac{1}{2} \sigma\right) y^{2}\right\}, \\
Y_{z}=-\frac{W}{2(\mathrm{I}+\sigma) I}\left\{\frac{\partial \chi}{\partial y}+(2+\sigma) x y\right\},
\end{array}\right\}
$$

where $I=$ the moment of inertia of the cross-section about its neutral axis.

The flexure function $\chi$ given by (I) cannot be expressed rationally in terms of $x$ and $y$, as Love describes in his "Mathematical Theory of Elasticity."(1) Therefore, the shearing stresses cannot be expressed in terms of $x$ and $y$ from the equations ( 1 ) and (2). We are now to obtain these expressions in terms of $\xi$ and $\eta$.

Transforming the equations (2) to express them in terms of $\xi$ and $\eta$, we have

$$
\begin{array}{r}
X_{z}=-\frac{W c^{2}}{2(\mathrm{I}+\sigma) I}\left\{\frac{\mathrm{I}}{c^{3}\left(\cosh ^{2} \xi-\cos ^{2} \eta\right)}\left(\sinh \xi \cos \eta \frac{\partial \chi}{\partial \xi}-\cosh \xi \sin \eta \frac{\partial \chi}{\partial \eta}\right)\right. \\
\left.\quad+\frac{1}{2} \sigma \cosh ^{2} \xi \cos ^{2} \eta+\left(\mathrm{I}-\frac{1}{2} \sigma\right) \sinh ^{2} \xi \sin ^{2} \eta\right\}, \\
Y_{z}=-\frac{W c^{2}}{2(\mathrm{I}+\sigma) I}\left\{\frac{\mathrm{I}}{c^{3}\left(\cosh ^{2} \xi-\cos ^{2} \eta\right)}\left(\cosh \xi \sin \eta \frac{\partial \chi}{\partial \xi}+\sinh \xi \cos \eta \frac{\partial \chi}{\partial \eta}\right)\right. \\
+(2+\sigma) \cosh \xi \sinh \xi \cos \eta \sin \eta\}
\end{array}
$$

Differentiating the equation (I) with respect to $\xi$ and $\eta$, and substituting into the equations (3), we may obtain the shearing stress components $X_{z}$ and $Y_{z} ;$ - these expressions become too lengthy. But if we find the shearing stress components referring to the curvilinear orthogonal co-ordinates $\xi$, $\eta$, we may arrive at comparatively simple expressions.

(1) I.ove, Mathematical Theory of Elasticity, 3rd edition, p. 342. 
The shearing stress components on the cross-section referred to the co-ordinates $\xi, \eta$ are given by

$$
\left.\begin{array}{l}
\widehat{\xi_{z}}=X_{z} \cos (x, \xi)+Y_{z} \cos (y, \xi), \\
\overline{\eta_{z}}=X_{z} \cos \left(x, y_{j}\right)+Y_{z} \cos \left(y^{\prime}, y_{j}\right) .
\end{array}\right\}
$$

The direction cosines of the normals to the $\xi$ curve and to the $\eta$ curve are ${ }^{(1)}$

$$
\begin{array}{ll}
\cos (x, \xi)=\frac{\mathrm{I}}{h_{1}} \frac{\partial \xi}{\partial x}, & \cos \left(y^{\prime}, \xi\right)=\frac{\mathrm{I}}{l_{1}} \frac{\partial \xi}{\partial y^{\prime}}, \\
\cos (x, y)=\frac{\mathrm{I}}{h_{l}} \frac{\partial \eta}{\partial x}, & \cos \left(y^{\prime}, \eta\right)=\frac{\mathrm{I}}{h_{2}} \frac{\partial \eta}{\partial y^{\prime}},
\end{array}
$$

where

$$
\begin{aligned}
& h_{1}^{2}=\left(\frac{\partial \xi}{\partial x}\right)^{2}+\left(\frac{\partial \xi}{\partial y^{\prime}}\right)^{2}, \\
& h_{2}^{2}=\left(\frac{\partial \eta}{\partial x}\right)^{2}+\left(\frac{\partial \eta}{\partial y}\right)^{2} .
\end{aligned}
$$

In this case

$$
h_{1}=h_{2}=\frac{1}{c\left(\cosh ^{2} \xi-\cos ^{2} \eta\right)^{1 / 2}}
$$

Hence we have, from (4),

$$
\begin{aligned}
& \widehat{\xi_{i}}=\frac{1}{\left(\cosh ^{2} \xi-\cos ^{2} \eta\right)^{1 / 2}}\left(\sinh \xi \cos \eta X_{z}+\cosh \xi \sin \eta Y_{z}\right), \\
& \widehat{\gamma_{j i}}=\frac{\mathrm{I}}{\left(\cosh ^{2} \xi-\cos ^{2} \eta\right)^{1 / 2}}\left(-\cosh \xi \sin \eta X_{z}+\sinh \xi \cos \eta Y_{z}\right) .
\end{aligned}
$$

Substituting the equations (3) in these equations, we have

$$
\begin{aligned}
& \widehat{\xi_{i}}=-\frac{W_{c}^{2}}{2(\mathrm{I}+\sigma) I\left(\cosh ^{2} \xi-\cos ^{2} \eta\right)^{1 / 2}}\left[\frac{1}{c^{3}} \frac{\partial \gamma}{\partial \xi}\right. \\
& -\cos \eta\left\{\left(\frac{1}{16}-\frac{1}{4} \sigma\right) \sinh \xi-\left(\frac{3}{16}+\frac{1}{8} \sigma\right) \sinh 3 \xi\right\} \\
& \left.+\cos 3 \eta\left\{\left(\frac{1}{16}-\frac{1}{8} \sigma\right) \sinh \xi-\frac{3}{16} \sinh 3 \xi\right\}\right] \text {, } \\
& \widehat{\gamma_{i}}=-\frac{W c^{2}}{2(\mathrm{I}+\sigma) I\left(\cosh ^{2} \xi-\cos ^{2} \eta\right)^{1 / 2}}\left[\frac{\mathrm{I}}{c^{3}} \frac{\partial \gamma}{\partial \eta}\right.
\end{aligned}
$$

(1) Love, Mathematical Theory of Elaticity, 3rd edition, p. 52. 
Sharing Stressis in Biams of Cirtain Cross-Sictions.

$$
\begin{aligned}
& +\sin \eta\left\{\left(\frac{1}{16}-\frac{1}{4} \sigma\right) \cosh \xi-\left(\frac{1}{16}-\frac{1}{8} \sigma\right) \cosh 3 \xi\right\} \\
& \left.-\sin 3 \eta\left\{\left(\frac{3}{16}+\frac{1}{8} \sigma\right) \cosh \xi-\frac{3}{16} \cosh 3 \xi\right\}\right],
\end{aligned}
$$

which are the general forms of the shearing stress components referred to the curvilinear orthogonal co-ordinates $\xi, \eta$. Differentiating the equation ( $\mathrm{I}$ ) with respect to $\xi$ and $\eta$, and substituting in the equations (6), we have the shearing stresses on the crosssection, which are as follows :-

$$
\begin{aligned}
& \widehat{\xi_{\delta}}=-\frac{W c^{2}}{2(\mathrm{I}+\sigma) l\left(\cosh ^{2} \xi-\cos ^{2} \eta\right)^{1 / 2}}\left\{\operatorname { c o s } \eta \left[\left(\frac{3}{16}+\frac{1}{8} \sigma\right) \sinh \xi\right.\right. \\
& +\left(\frac{3}{16}+\frac{1}{8} \sigma\right) \sinh 3 \xi-\left(\frac{3}{4}+\frac{1}{2} \sigma\right)\left\{\cosh \xi_{0} \cosh \xi_{1} \cosh \left(\xi_{0}+\xi_{1}\right) \sinh \xi\right. \\
& \left.\left.-\sinh \xi_{0} \sinh \xi_{1} \sinh \left(\xi_{0}+\xi_{1}\right) \cosh \xi\right\}\right] \\
& +\cos 3 \eta\left[\left(\frac{1}{16}-\frac{1}{8} \sigma\right) \sinh \xi\right. \\
& \left.-\left(\frac{1}{1.6}-\frac{1}{8} \sigma\right) \frac{\sinh \xi_{11} \sinh 3\left(\xi-\xi_{1}\right)+\sinh \xi_{1} \sinh 3\left(\xi_{0}-\xi\right)}{\sinh 3\left(\xi_{0}-\xi_{1}\right)}\right] ;, \\
& \widehat{\gamma_{i j}}=\frac{W c^{2}}{2(1+\sigma) \Gamma\left(\cosh ^{2} \xi-\cos ^{2} \eta\right)^{1 / 2}}\left\{\operatorname { s i n } \eta \left[\left(\frac{3}{16}+\frac{1}{8} \sigma\right) \cosh \xi\right.\right. \\
& +\left(\frac{1}{16}-\frac{1}{8} \sigma\right) \cosh 3 \xi-\left(\frac{3}{4}+\frac{1}{2} \sigma\right)\left\{\cosh \xi_{0} \cosh \xi_{1} \cosh \left(\xi_{0}+\xi_{1}\right) \cosh \xi\right. \\
& \left.\left.-\sinh \xi_{0} \sinh \xi_{1} \sinh \left(\xi_{0}+\xi_{1}\right) \sinh \xi\right\}\right] \\
& +\sin 3 \eta\left[\left(\frac{3}{16}+\frac{1}{8} \sigma\right) \cosh \xi\right. \\
& \left.-\left(\frac{1}{16}-\frac{1}{8} \sigma\right) \frac{\sinh \xi_{10} \cosh 3\left(\xi-\xi_{1}\right)-\sinh \xi_{1} \cosh 3\left(\xi_{0}-\xi\right)}{\sinh 3\left(\xi_{0}-\xi_{1}\right)}\right] \int^{\prime} \cdot
\end{aligned}
$$

On the neutral axis of the cross-section, where $\eta=\pi / 2$, we have $\widehat{\xi_{j}}=0$. Therefore, the shearing stresses on the neutral axis are parallel to the vertical axis, and their distribution is as shown in Fig. 2. In the figure, the outer and inner boundaries are the ellipses of $\xi_{0}=\mathbf{I} .0$ and $\xi_{1}=0.5$ respectively.

Let $a_{0}$ and $b_{0}=$ semi-major and semi-minor axes of outer ellipse, 
$a_{1}$ and $b_{1}=$ semi-major and semi-minor axes of inner ellipse, then we have

$$
\begin{array}{ll}
a_{0} / c=\mathrm{I} .543, & b_{0} / c=1.175, \\
a_{1} / c=\mathrm{I} .128, & b_{1} / c=0.52 \mathrm{I},
\end{array}
$$

in which $2 c$ is the length between the common foci. The stresses are given in their ratio to the mean shearing stress taken over the area of the cross-section, i. e., $W / A$, where $A$ is the sectional area of the cross-section. In the calculation, Poisson's ratio is taken to be $\mathrm{I} / 4$.

Special Case 1.-Whin $\xi_{0}-\xi_{1}$ is very small. In this case, we have a thin hollow elliptic cylindrical beam. If we neglect the

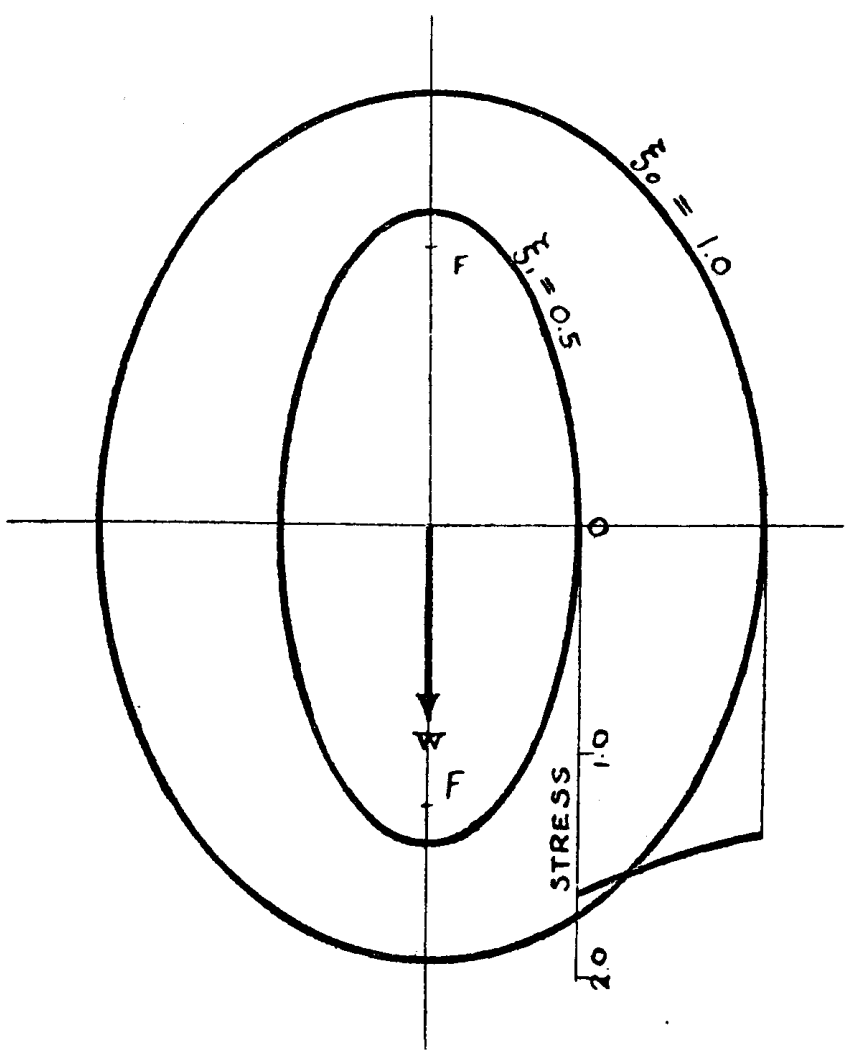

Fig. 2. Distribution tof Shearing Stresses on the Neutral Axis. 
squares and higher powers of $\left(\tilde{\xi}_{0}-\tilde{\xi}_{1}\right)$, we have $\widehat{\xi_{s}}=0$, which shows that the shearing stresses on the cross-section are tangential to the wall of the beam.

The total sum of the shearing stresses on the cross-section taken over the thickness on the line normal to the wall of the bea'n is

$$
S=\int_{\xi_{1}}^{\xi_{0}} \widetilde{\gamma_{j} \sigma} d n_{1}
$$

where $d n_{1}$ is the length of the normal to the curve of the family $\xi$ intercejted between the curves $\xi$ and $\xi+d \xi$, and is given by

$$
d n_{1}=\frac{d \xi}{h_{1}}
$$

From (5), we have

$$
d n_{1}=c\left(\cosh ^{2} \xi-\cos ^{2} \gamma\right)^{1 / 2} d \xi
$$

Therefore, we have

$$
\begin{aligned}
S & =\int_{\xi_{1}}^{\xi_{0}} \bar{\eta} \cdot c\left(\cosh ^{2} \xi-\cos ^{2} \eta\right)^{1 / 2} d \xi \\
& =-\frac{W c^{3}}{12 I}\left\{\left(\sinh 3 \xi_{0}-\sinh 3 \xi_{1}\right) \sin \eta-\left(\sinh \xi_{0}-\sinh \xi_{1}\right) \sin 3 \eta\right\} .
\end{aligned}
$$

Neglecting the squares and higher powers of $\left(\xi_{0}-\xi_{1}\right)$, we have

$$
S=-\frac{W c^{3}\left(\xi_{0}-\xi_{1}\right)}{I}\left(\frac{1}{4} \cosh 3 \xi^{\prime \prime} \sin \eta-\frac{1}{1} \cosh \xi^{\prime} \sin 3 \gamma_{j}\right)
$$

where $\xi^{\prime}=\left(\xi_{0}+\xi_{1}\right) / 2$, i.e., the value of $\xi$ for the wall of the beam. The thickness of the wall is

$$
t=\int_{\xi_{1}}^{\xi_{0}} d n_{1}
$$

(1) Love, Mathematical Theory of Elasticity, 3rd edition, p. 52. 


$$
=\int_{\xi_{1}}^{\xi_{0}} c\left(\cosh ^{2} \xi-\cos ^{2} \eta\right)^{1 / 2} d t_{5}
$$

As $\left(\xi_{0}-\xi_{1}\right)$ is very small, we may have

$$
t=c\left(\cosh ^{2} \xi^{\prime}-\cos ^{2} \eta\right)^{1 / 2}\left(\xi_{0}-\xi_{1}\right) \text {. }
$$

Therefore, the mean shearing stress taken over the thickness is

$$
q=-\frac{W c_{c}^{\prime \prime}}{I\left(\cosh ^{2} \xi^{\prime}-\cos ^{2} \eta\right)^{1 / 2}}\left(\frac{1}{4} \cosh 3 \xi^{\prime} \sin \eta-\frac{1}{12} \cosh \xi^{\prime} \sin 3 \gamma\right) .
$$

Now, the moment of the area above the point considered about the neutral axis is given by

$$
m=\int x d c
$$

and

$$
d c=t \cdot d n
$$

where $d n_{2}=$ the length of the normal to the curve of the family $\eta$ intercepted between the curves $\eta$ and $\eta+d r$. This length of the normal is given by a similar equation as that for $d_{n_{1}}$, and is

$$
d n=\frac{d \eta}{l}
$$

Therefore, from (5), we get

$$
d n_{2}=c\left(\cosh ^{2} \xi-\cos ^{2} \eta\right)^{1 / 2} d r_{1}
$$

Thus the moment is

$$
\begin{aligned}
m & =2 \int_{\eta}^{\pi} c^{3} \cosh \xi^{\prime} \cos \eta\left(\cosh ^{2} \xi^{\prime}-\cos ^{2} \eta\right)\left(\xi_{0}-\xi_{1}\right) d \eta \\
& =-2 c^{3}\left(\xi_{0}-\xi_{1}\right)\left(\frac{1}{4} \cosh \xi^{\prime} \sin \eta-\frac{1}{12} \cosh \xi^{\prime} \sin 3 y^{\prime}\right) .
\end{aligned}
$$

Therefore, (8) may be reduced to the from

$$
q=\frac{I W m}{2 t I}
$$


which is the formula used for the practical calculation of the shearing stress at any point of a thin hollow cylindrical beam. This formula for the practical calculation was introduced by Prof. Suyehiro(1) from his mathematical calculation for a thin hollow circular cylindrical beam. It will be seen that the same formula can be applied not only to circular sections but also to elliptic sections, the latter being evidently more general than the former.

Special Case 2.-When $\xi_{1}$ is very small. In this case, we have an elliptic cylindrical beam having a fine groove along the major axis extending very nearly between the foci. If $\xi_{1}=0$, the fine groove becomes a hair crack of the length equal to the distance between the foci.

Now, if we put $\xi_{1}=0$ in the flexure function (I), we have

$$
\begin{aligned}
\chi= & c^{3}\left\{\left(\frac{1}{16}-\frac{1}{4} \sigma\right) \sinh \xi_{0}-\left(\frac{3}{16}+\frac{1}{8} \sigma\right) \sinh 3 \xi_{0}\right\} \frac{\cosh \xi}{\sinh \xi_{0}} \cos \eta \\
& -c^{3}\left\{\left(\frac{1}{16}-\frac{1}{8} \sigma\right) \sinh \xi_{0}-\frac{3}{16} \sinh 3 \xi_{0}\right\} \frac{\cosh 3 \xi}{3 \sinh 3 \xi_{0}} \cos 3 \eta
\end{aligned}
$$

which is the same form as the flexure function for an elliptic crosssection.(:) Therefore, the distribution of the shearing stresses on an elliptic section is not influenced by the presence of a crack along the vertical axis of the cross-section.

(b) When the major axis is horisontal. - Take the axis of $y$ vertically downwards. The flexure function for this section is

$$
\begin{array}{r}
x^{\prime}=-c^{3} \sin \eta\left[\left(\frac{1}{4}-\frac{1}{8} \sigma\right) \sinh \xi+\left(\frac{3}{4}+\frac{1}{2} \sigma\right)\right. \\
-\cosh \xi_{0} \cosh \xi_{1} \sinh \left(\xi_{4}+\xi_{1}\right) \cosh \xi \\
\left.\left.-\sinh \xi_{0} \sinh \xi_{1} \cosh \left(\xi_{0}+\xi_{1}\right) \sinh \xi\right\}\right]
\end{array}
$$

(1) Jour. Soc. Nav. Arch., Tơkyô, Vol. XI.

(2) Iove, Mathematical Theory of Elasticity, 3rd edition, p. $34 \mathrm{I}$. 
$-c^{3} \sin 3 \eta\left[\frac{1}{16} \sinh 3 \xi\right.$

$$
\left.+\left({ }_{16}^{1}-\frac{1}{8} \sigma\right) \frac{\cosh \xi_{0} \cosh 3\left(\xi-\xi_{1}\right)-\cosh \xi_{1} \cosh 3\left(\xi_{0}-\xi\right)}{3 \sinh 3\left(\xi_{0}-\xi_{1}\right)}\right] .
$$

The deduction of this function is given in Appendix I.

If the load $W$ is directed parallel to the axis of $y$, the shearing stress components on the cross-section when the section is symmetrical about the vertical centre line, are given by

$$
\begin{aligned}
& X_{z}=-\frac{W}{2(\mathrm{I}+\sigma) I^{\prime}}\left\{\frac{\partial \chi^{\prime}}{\partial x}+(2+\sigma) x y\right\}, \\
& Y_{z}=-\frac{W}{2(\mathrm{I}+\sigma) I^{\prime}}\left\{\frac{\partial \chi^{\prime}}{\partial y}+\left(\mathrm{I}-\frac{1}{2} \sigma\right) x^{2}+\frac{1}{2} \sigma y^{2}\right\},
\end{aligned}
$$

where $I^{\prime}=$ the moment of inertia of the cross-section about the neutral axis.

As in the previous case, the shearing stress components may be transformed into those referred to the curvilinear orthogonal co-ordinates $\xi, \eta$, and we have

$$
\left.\begin{array}{r}
\widehat{\xi \xi}=\frac{W c^{2}}{2(1+\sigma) I^{\prime}\left(\cosh ^{2} \xi-\cos ^{2} \eta\right)^{1 / 2}}\left\{\operatorname { s i n } \eta \left[\left(\frac{3}{16}+\frac{1}{8} \sigma\right) \cosh \xi\right.\right. \\
-\left(\frac{3}{16}+\frac{1}{8} \sigma\right) \cosh 3 \xi+\left(\frac{3}{4}+\frac{1}{2} \sigma\right)\left\{\cosh \xi_{0} \cosh \xi_{1} \sinh \left(\xi_{0}+\xi_{1}\right) \sinh \xi\right. \\
\left.\left.\left.-\sinh \xi_{0} \sinh \xi_{1} \cosh \left(\xi_{0}+\xi_{1}\right) \cosh \xi\right\}\right]\right) \\
-\sin 3 \eta\left[\left(\frac{1}{16}-\frac{1}{8} \sigma\right) \cosh \xi\right.
\end{array}\right\},
$$




$$
\left.\left.-\sinh \xi_{0} \sinh \xi_{1} \cosh \left(\xi_{0}+\xi_{1}\right) \sinh \xi\right\}\right]
$$

$-\cos 3 \eta\left[\left(\frac{3}{16}+\frac{1}{8} \sigma\right) \sinh \xi\right.$

$$
\left.\left.\left.-\left(\frac{3}{16}-\frac{1}{8} \sigma\right) \frac{\cosh \xi_{0} \cosh 3\left(\xi-\xi_{1}\right)-\cosh \xi_{1} \cosh 3\left(\xi_{0}-\xi\right)}{\sinh 3\left(\xi_{0}-\xi_{1}\right)}\right]\right\} \cdot\right)
$$

Substituting $\eta=0$, we have $\widehat{\xi z}=0$. There.ore, on the neutral axis, the shearing stresses on the cross-section are all parallel to the vertical axis. The distribution of the shearing stresses on this line is shown in Fig. 3. In this figure, as in the previous example, the outer and inner boundaries are the ellipses of $\xi_{0}=1.0$ and $\xi_{1}=0.5$ respectively, and the stresses are given in their ratio to the mean shearing stress taken over the area of the cross-section, i. e., $W / A$. Poisson's ratio is taken to be $1 / 4$.

Spcial Casi $1 .-$ When $\xi_{0}-\xi_{1}$ is very small. As in the previous case, neglecting the squares and higher powers of $\left(\xi_{0}-\xi_{1}\right)$, we have $\widehat{\xi z}=0$. Therefore, the shearing stresses on the cross-section of a thin hollow elliptic cylindrical beam are tangential to the wall of the beam, and it can easily be shown that the mean shearing stress taken over the thickness is

$$
q=\frac{W c^{2}}{l^{\prime}\left(\cosh ^{2} \xi^{\prime}-\cos ^{2} \eta\right)^{1 / 2}}\left(\frac{1}{4} \sinh 3 \xi^{\prime} \cos \eta-\frac{1}{12} \sinh \xi^{\prime} \cos 3 \eta\right),
$$

which may be transformed into

$$
q=\frac{W n^{\prime}}{2 t I^{\prime}}
$$

where $m^{\prime}=$ the moment about the neutral axis of the area of the cross-section above the point considered. Therefore, we have the same result as in the previous case, that the resultant shearing stress 
at any point on the cross-section is in the direction of the tangent to the wall of the beam and can be obtained by the formula for the practical calculation of the shearing stress given by the equation (II).

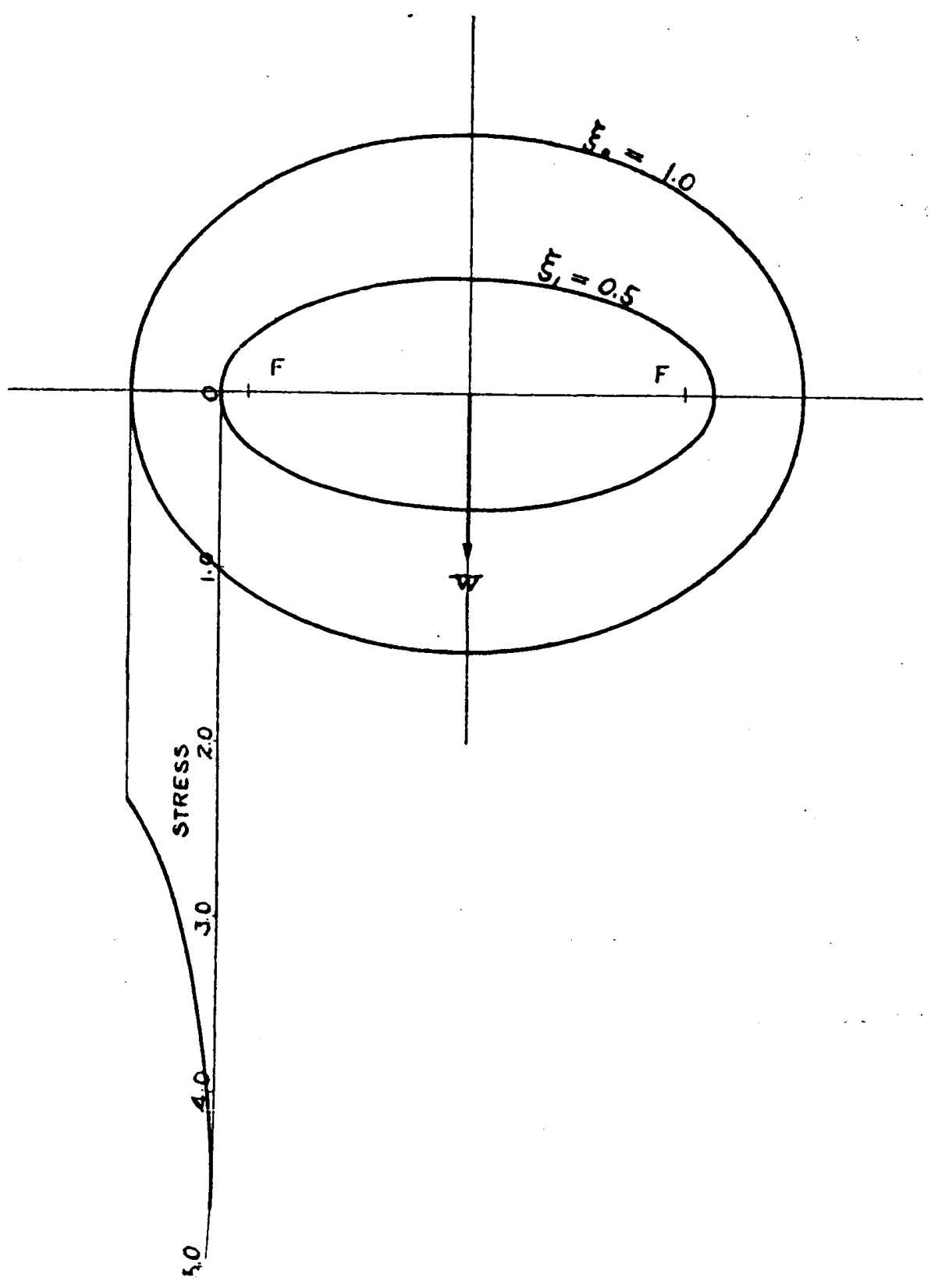

Fig. 3. Distribution of Shearing Stresses on the Neutral Axis. 
Special Case 2.- Whon $\xi_{1}$ is vory small. In this case, we have an elliptic cylindrical beam having a horizontal crack on the major axis extending very nearly between the foci.

If we put $\xi_{1}=0$ in the flexure function (9), then we have

$$
\begin{aligned}
\chi^{\prime}= & -c^{3}\left\{\left(\frac{1}{4}-\frac{1}{8} \sigma\right) \sinh \xi+\left(\frac{3}{4}+\frac{1}{2} \sigma\right) \cosh \xi_{0} \sinh \xi_{0} \cosh \xi\right\} \sin \eta \\
& -c^{3}\left\{\frac{1}{16} \sinh 3 \xi+\left(\frac{1}{16}-\frac{1}{8} \sigma\right) \frac{\cosh \xi_{0} \cosh 3 \xi-\cosh 3\left(\xi_{0}-\xi\right)}{3 \sinh 3 \xi_{0}}\right\} \sin 3 \eta
\end{aligned}
$$

We may easily show that the flexure function for an elliptic scction when the major axis is horizontal, is

$$
\begin{aligned}
\chi^{\prime}= & -c^{3}\left\{\left(\frac{1}{16}-\frac{1}{4} \sigma\right) \cosh \xi_{0}+\left(\frac{3}{16}+\frac{1}{8} \sigma\right) \cosh 3 \xi_{0}\right\} \frac{\sinh \xi}{\cosh \xi_{0}} \sin \eta \\
& -c^{3}\left\{\left(\frac{1}{16}-\frac{1}{8} \sigma\right) \cosh \xi_{0}+\frac{3}{16} \cosh 3 \xi_{0}\right\} \frac{\sinh 3 \xi}{3 \cosh 3 \xi_{0}} \sin 3 \eta
\end{aligned}
$$

which is not identical to the flexure function (12). Therefore, it will be seen that, owing to the presence of a horizontal crack in the section of an elliptic beam, the distribution of the shearing stresses becomes different from that of a solid elliptic beam.

In the limiting case $\xi_{1}=0$, it can be shown that the shearing stress components can be obtained simply by putting $\xi_{1}=0$ in the equations (Io), and we have

$$
\begin{aligned}
& \widehat{\xi \xi=}=\frac{W c^{2}}{2(1+\sigma) I^{\prime}\left(\cosh ^{2} \xi-\cos ^{2} \eta\right)^{1 / 2}}\left[\operatorname { s i n } \eta \left\{\left(\underset{1 \sigma}{3}+\frac{1}{8} \sigma\right) \cosh \xi\right.\right. \\
& -\left(\frac{3}{16}+\frac{1}{8} \sigma\right) \cosh 3 \frac{5}{5}+\left(\begin{array}{l}
3 \\
8
\end{array}+\frac{1}{4} \sigma\right) \sinh 2 \xi_{0} \sinh \xi ; \\
& -\sin 3 \pi\left(\frac{1}{16}-\frac{1}{8} \sigma\right) \cosh \xi-\left(\frac{1}{16}-\frac{1}{8} \sigma\right) \cosh 35 \\
& \left.\left.+\left(\frac{1}{s}-\frac{1}{4} \sigma\right) \frac{\sinh \xi_{0} \sinh 2 \xi_{0}}{\sinh 3 \xi_{0}} \sinh 3 \xi_{j}\right)\right]
\end{aligned}
$$




$$
\begin{aligned}
\widehat{\eta z}=\frac{W c^{2}}{2(1+\sigma) \Gamma\left(\cosh ^{2} \xi-\cos ^{2} \eta\right)^{1 / 2}} & {\left[\operatorname { c o s } \eta \left\{\left(\frac{3}{16}+\frac{1}{8} \sigma\right) \sinh \xi\right.\right.} \\
& \left.-\left(\frac{1}{16}-\frac{1}{8} \sigma\right) \sinh 3 \xi+\left(\frac{3}{8}+\frac{1}{4} \sigma\right) \sinh 2 \xi_{0} \cosh \xi\right\} \\
- & \cos 3 \eta\left\{\left(\frac{3}{16}+\frac{1}{8} \sigma\right) \sinh \xi-\left(\frac{1}{16}-\frac{1}{8} \sigma\right) \sinh 3 \xi\right. \\
& \left.\left.+\left(\frac{1}{8}-\frac{1}{4} \sigma\right) \frac{\sinh \xi_{0} \sinh 2 \xi_{0}}{\sinh 3 \xi_{0}} \cosh 3 \xi\right\}\right] .
\end{aligned}
$$

When $\xi$ and $\eta$ are very small, we have the following equations, the higher powers of $\xi$ and $\eta$ being neglected,

$$
\begin{aligned}
& {[\overline{\xi \tilde{s}}]_{\xi, \eta=\text { very small }}=0 \text {, }} \\
& {[\widehat{\eta \sigma}]_{\xi, \eta=\text { very small }}=\frac{W c^{2}}{2(1+\sigma) \Gamma^{\prime}\left(\xi^{2}+\eta^{2}\right)^{1 / 2}}\left\{\left(\frac{3}{8}+\frac{1}{4} \sigma\right) \sinh 2 \xi_{0}\right.} \\
& \left.-\left(\frac{1}{8}-\frac{1}{4} \sigma\right) \frac{\sinh \xi_{0} \sinh 2 \xi_{0}}{\sinh 3 \xi_{0}}\right\} \text {. }
\end{aligned}
$$

It is worth specially mentioning that the latter may have a very large value. At a point near the foci of the ellipse, the shearing stress is nearly tangential to one of the family of the confocal ellipses passing through that point, and its magnitude is very large. At the very edge of the crack, i. e., where $\xi=\eta=0$, the shearing stress becomes infinity and is in the direction parallel to the vertical axis.

Now, let $\xi_{0}=4.0$, then we have

$$
\begin{aligned}
& \text { the semi-major axis }=a_{0}=27.308 \mathrm{c}, \\
& \text { the semi-minor axis }=b_{0}=27.290 \mathrm{c},
\end{aligned}
$$

in which $2 c=$ the length between the foci. This ellipse may practically be taken as a circle. Thus the section taken corresponds to a circle with a horizontal crack at the centre having the length of $1 / 27 \cdot 3^{\text {th }}$ of the diameter. The distribution of the shearing stresses 
on the neutral axis in such a section is shown in Fig. 4. The stresses in the figure are represented in their ratio to the mean shearing stress taken over the area of the cross-section, $W / A$. Again, Poisson's ratio is taken to be $\mathrm{r} / 4$. In the same figure,

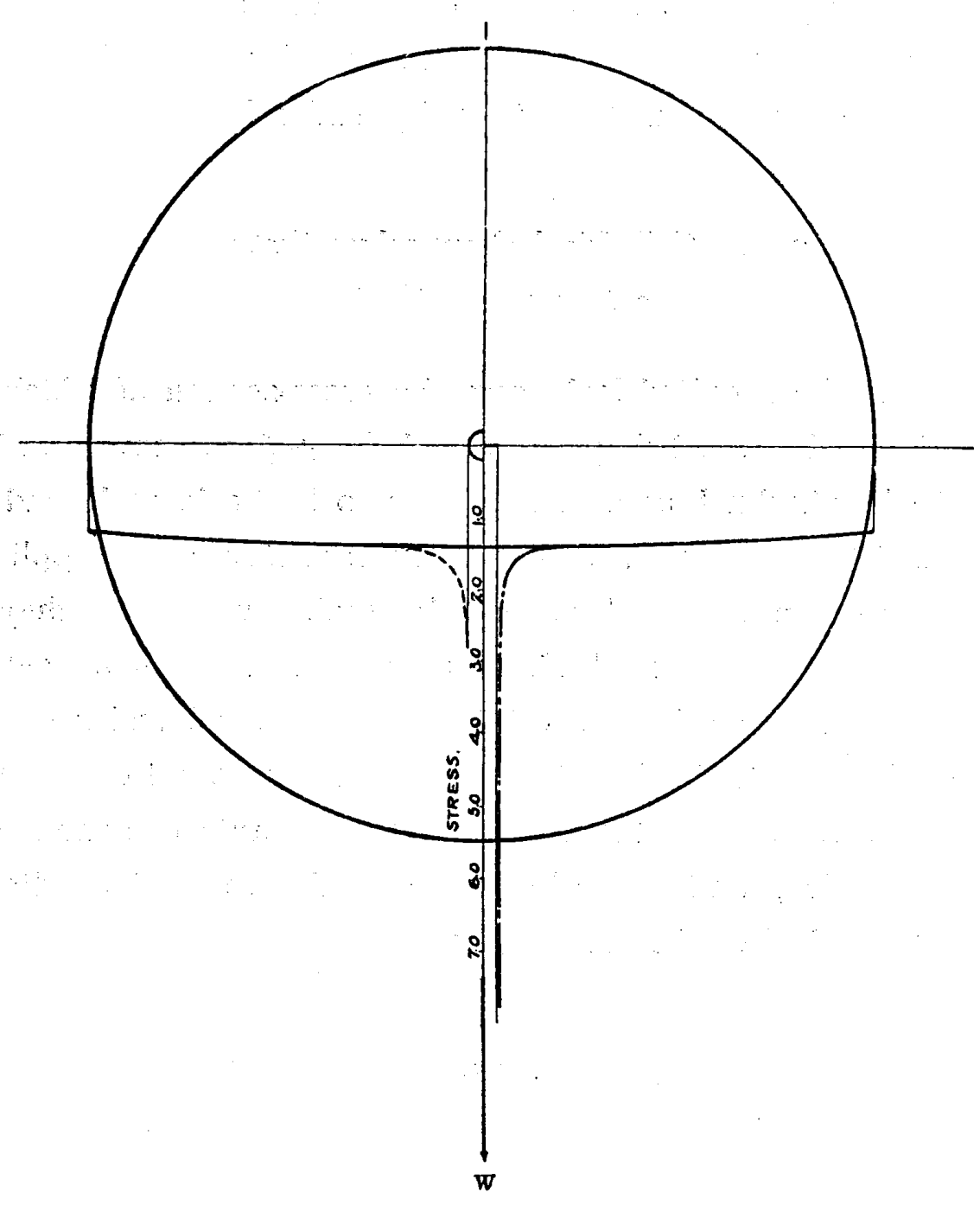

Fig. 4. Distributions of Shearing Stresses on the Neutral Axis. Solid Circular Section.

Circular Saction with Horizontal Crack. Circular Section with Circular Cavity. 
the distribution of the shearing stresses on the neutral axis of a solid circular section and that for a circular section with a small circular cavity at the centre having the diameter of $1 / 27.3^{\text {th }}$ of that of the section are also shown. It will be noticeable that the shearing stress on the neutral axis at the circumference of a very small circular cavity at the centre of a circular section is just twice the shearing stress at the corresponding point of a solid circular section of the same diameter. (See Appendix II.)

\section{A Cylindrical Bcam zohosc Siction is a Sector of a Circle.}

Let us take a cylindrical beam the cross-section of which is a sector of a circle bounded by $r=a$ and $\theta= \pm \beta$ as shown in Fig. 5 . Take the longitudinal axis of the beam to be horizontal, and one end of which to be fixed, and suppose that forces are applied to the cross-section at the free end in such a way that they are equivalent to a vertical load $W$ acting on a line through the centroid of the section. We select the origin at the fixed end, and the axis of $\approx$ along the longitudinal axis through the centroid of the crosssection. Further, take the axis of $x$ on the axis of symmetry of the cross-section, and that of $y$ perpendicular to it. The distance of the centroid $G$ of the section from the centre $O$ of the circle is given by

$$
k=\frac{2}{3} a \frac{\sin \beta}{\beta} \text {. }
$$

(a) When the axis of symmetry of the section is vertical.Take the axis of $x$ vertically downwards. The flexure function $\chi$ for this section referred to polar co-ordinates, the origin of which is at the centre of the bounding circle of the sector, is 


$$
\begin{aligned}
\chi=-\frac{1}{2} \sigma k^{2} r \cos \theta-\frac{1}{2} k r^{2} \cos 2 \theta & -\left\{\left(\frac{1}{4}-\frac{1}{2} \sigma\right) \frac{\sin \beta}{3 \sin 3 \beta}-\frac{1}{4}\right\} r^{3} \cos 3^{\theta} \\
& \left.+\frac{4 a^{3} \beta^{2} \sin \beta}{\pi} \sum_{n=1}^{\infty} B_{n}\left(\frac{r}{a}\right)^{n \pi / \beta} \cos \frac{n \pi \theta}{\beta}, \ldots \text { (I } 3\right)
\end{aligned}
$$

where

$$
B_{n}=\frac{(-\mathrm{I})^{n}}{n} \frac{n^{2} \pi^{2} \sigma-3(\mathrm{I}+\sigma) \beta^{2}}{\left(n^{2} \pi^{2}-\beta^{2}\right)\left(n^{2} \pi^{2}-3^{2} \beta^{2}\right)}
$$

For finding the above function, see Appendix $\mathrm{I}$.

If we take rectangular co-ordinate axes $x^{\prime}$ and $y^{\prime}$ through the centre of the circle, and parallel to the axes of $x$ and $y$, the expressions (2) become

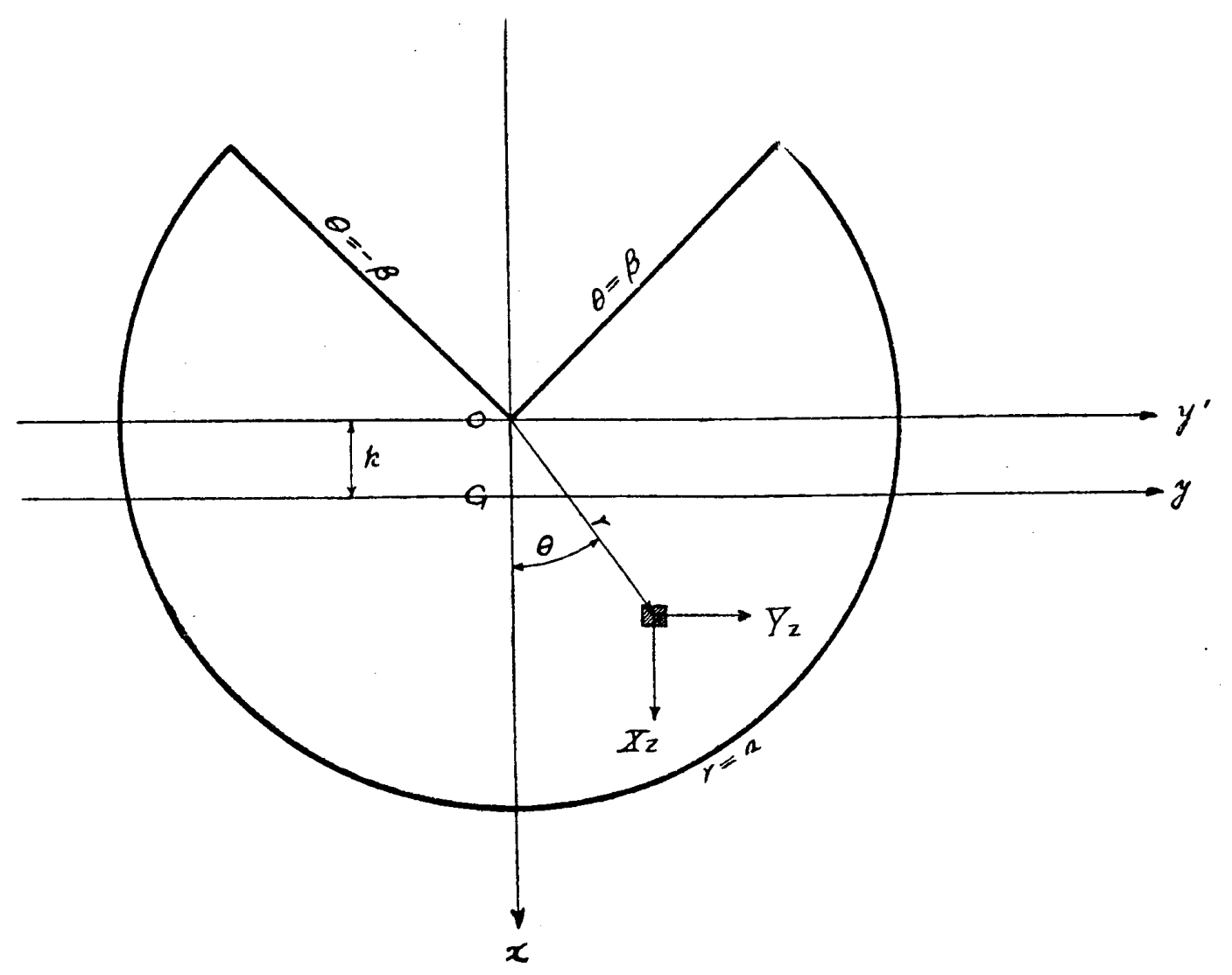

Fig. 5. 
164

$$
\begin{aligned}
& X_{z}=-\frac{W}{2(\mathrm{I}+\sigma) I}\left\{\frac{\partial \chi}{\partial x^{\prime}}+\frac{1}{2} \sigma\left(x^{\prime}-k\right)^{2}+\left(\mathrm{I}-\frac{1}{2} \sigma\right) y^{\prime \prime}\right\} \\
& Y_{z}=-\frac{W}{2(\mathrm{I}+\sigma) I}\left\{\frac{\partial \chi}{\partial y^{\prime}}+(2+\sigma)\left(x^{\prime}-k\right) y^{\prime}\right\} .
\end{aligned}
$$

Transforming these again to the polar co-ordinates, we have

$$
\begin{aligned}
& X_{z}=-\frac{W}{2(\mathrm{I}+\sigma)} I\left\{\cos \theta \frac{\partial \chi}{\partial r}-\sin \theta\right. \frac{\mathrm{I}}{r} \frac{\partial \chi}{\partial \theta} \\
&\left.+\frac{1}{2} \sigma(r \cos \theta-k)^{2}+\left(\mathrm{I}-\frac{1}{2} \sigma\right) r^{2} \sin ^{2} \theta\right\} \\
& Y_{z}=-\frac{W}{2(\mathrm{I}+\sigma) I}\left\{\sin \theta \frac{\partial \chi}{\partial r}+\cos \theta \frac{\mathrm{I}}{r} \frac{\partial \chi}{\partial \theta}+(2+\sigma)(r \cos \theta-k) r \sin \theta\right\}
\end{aligned}
$$

Differentiating (13) with respect to $r$ and $\theta$, and substituting in the above equations, we have

$$
\begin{gathered}
X_{z}=-\frac{W}{2(\mathrm{I}+\sigma) I}\left[\frac{1}{2} r^{2}-(\mathrm{I}+\sigma) k r \cos \theta\right. \\
+\left\{\left(\frac{1}{4}+\frac{1}{2} \sigma\right)-\left(\frac{1}{4}-\frac{1}{2} \sigma\right) \frac{\sin \beta}{\sin 3 \beta}\right\} r^{2} \cos 2 \theta \\
\left.+4 \alpha^{2} \beta \sin \beta \sum_{n=1}^{\infty} B_{n} n\left(\frac{r}{a}\right)^{n \pi / \beta-1} \cos \left(\frac{n \pi}{\beta}-\mathrm{I}\right) \theta\right], \\
Y_{z}=-\frac{W}{2(\mathrm{I}+\sigma) I}[-(\mathrm{I}+\sigma) k r \sin \theta \\
+\left\{\left(\frac{1}{4}+\frac{1}{2} \sigma\right)+\left(\frac{1}{4}-\frac{1}{2} \sigma\right) \frac{\sin \beta}{\sin 3 \beta}\right\} r^{2} \sin 2 \theta \\
\left.-4 n^{2} \beta \sin \beta \sum_{n=1}^{\infty} B_{n} n\left(\frac{r}{a}\right)^{n \pi / \beta-1} \sin \left(\frac{n \pi}{\beta}-\mathrm{I}\right) \theta\right] .
\end{gathered}
$$

where $B_{a}$ is given by (14).

When $\beta=\pi / 3,2 \pi / 3$, or $\pi$, some of the coefficients of the terms in the above expressions become indeterminate, but we may easily find 
that they have all finite limits. Hence the shearing stress components given by the above equations are definite for all values of $\beta$ between $o$ and $\pi$.

When $r=0$, and $\beta$ is not equal to $\pi$, we have $X_{z}=0$ and $Y_{z}=0$. Therefore, the shearing stress at the corner of the sector where the two radial boundaries meet, is zero.

When $\beta=\pi$, the sector is a circle having a vertical crack extending from the centre to the circular boundary, and in this case, where $r=0$, i. e., at the centre, we have

$$
X_{z}=\frac{(3+2 \sigma) W a^{2}}{8(\mathrm{I}+\sigma) I}, \quad Y_{z}=0,
$$

which are the same as the shearing stress components at the centre of a solid circular section. (See Appendix II.) If we put $\beta=\pi$ in the flexure function (13), then we have

$$
\chi=-\left(\frac{3}{4}+\frac{1}{2} \sigma\right) a^{9} r \cos \theta+\frac{1}{4} r^{3} \cos 3^{\theta},
$$

which is the same as the flexure function for a circular section. (1) Hence we may conclude that the distribution of the shearing stresses in a circular cylindrical beam having a vertical crack extending from the centre to the boundary is the same as that of a solid circular section, or, that such a crack in the cross-section of a circular cylindrical beam does not affect the distribution of the shearing stresses.

(b) When the axis of symmetry of the section is horizontal.- We take the axis of $y$ vertically downwards. The flexure function $\chi^{\prime}$ for this section referred to polar co-ordinates, the origin of which is taken at the centre of the bounding circle of the sector, is

(1) Love, Mathematical Theory of Elasticity, 3rd edition, p. 340. 


$$
\begin{aligned}
\chi^{\prime}= & -\left(1-\frac{1}{2} \sigma\right) k^{2} r \sin \theta-\left(\frac{1}{2} \sigma \frac{1}{\cos 2 \beta}-1\right) k r^{2} \sin 2 \theta \\
& -\left\{\left(\frac{1}{4}-\frac{1}{2} \sigma\right) \frac{\cos \beta}{3 \cos 3 \beta}+\frac{1}{4}\right\} r^{3} \sin 3^{\theta} \\
& +\frac{16 a^{3} \beta^{2}}{\pi} \sum_{n=0}^{\infty} B_{2 n+1}\left(\frac{r}{a}\right)^{(2 n+1) \pi / 2 \beta} \sin \frac{(2 n+1) \pi \theta}{2 \beta},
\end{aligned}
$$

where

$$
\begin{aligned}
B_{2: i+1}=\frac{(-1)^{n+1}}{2 n+\mathrm{I}}\left\{\frac{\left(\frac{3}{4}+\frac{1}{2} \sigma\right) \cos \beta}{(2 n+\mathrm{I})^{2} \pi^{2}-2^{2} \beta^{2}}-\frac{2 \sigma k / a}{(2 n+1)^{2} \pi^{2}-2^{2} \cdot 2^{2} \beta^{2}}\right. \\
\left.-\frac{3\left(\frac{1}{4}-\frac{1}{2} \sigma\right) \cos \beta}{(2 n+1)^{2} \pi^{2}-2^{2} \cdot 3^{2} \beta^{2}}\right\}
\end{aligned}
$$

For the deduction of this function, see Appendix I.

When the load $W$ is directed parallel to the axis of $y$, the shearing stress components on the cross-section referred to the co-ordinates $x, y$ are given by

$$
\left.\begin{array}{l}
X_{z}^{r}=\mu \tau\left(\frac{\partial \phi}{\partial x}-y\right)-\frac{W}{2(\mathrm{I}+\sigma) \Gamma}\left\{\frac{\partial \chi^{\prime}}{\partial x}+(2+\sigma) x y\right\}, \\
Y_{z}=\mu \tau\left(\frac{\partial \phi}{\partial y}+x\right)-\frac{W}{2(\mathrm{I}+\sigma) I}\left\{\frac{\partial \chi^{\prime}}{\partial y}+\left(\mathrm{I}-\frac{1}{2} \sigma\right) x^{2}+\frac{1}{2} \sigma y^{2}\right\},
\end{array}\right\}
$$

where $\phi$ is the torsion function for the section, $\mu$ the modulus of rigidity, and $\tau$ the twist of the beam. The terms that contain $\tau$ are of the same form as those for the stress components in the torsion problem; and they express a system of stresses on the cross-section, which are equivalent to a couple about the axis of $z$ of the moment

$$
\mu \tau \iint\left(x^{2}+y^{2}+x \frac{\partial \phi}{\partial y}-y \frac{\partial \phi}{\partial x}\right) d x d y \text {. }
$$

The terms which contain $W$ will give rise to a couple about the same axis of moment 


$$
\frac{W}{2(\mathrm{I}+\sigma) I^{\prime}} \iint\left\{y \frac{\partial \chi^{\prime}}{\partial x}-x \frac{\partial \chi^{\prime}}{\partial y}-\left(\mathrm{I}-\frac{1}{2} \sigma\right) x^{3}+\left(2+\frac{1}{2} \sigma\right) x y^{2}\right\} d x d y .
$$

And, we have to adjust $\tau$ to make the sum of these couples vanish; the stresses on the cross-section must not yield any couple about the axis of $z$.

Now, the function $\psi$ of the torsion problem for this section is

$$
\psi=\frac{1}{2} r^{2} \frac{\cos 2 \theta}{\cos 2 \beta}+a^{2} \sum_{n=0}^{\infty} A_{2 n+1}\left(\frac{r}{a}\right)^{(2 n+1) \pi / 2 \beta} \cos \frac{(2 n+\mathrm{I}) \pi \theta}{2 \beta}
$$

where

$$
A_{2: l+1}=(-\mathrm{I})^{n+1}\left\{\frac{\mathrm{I}}{(2 n+\mathrm{I}) \pi-4 \beta}-\frac{2}{(2 n+\mathrm{I}) \pi}+\frac{\mathrm{I}}{(2 n+\mathrm{I}) \pi+4 \beta}\right\}
$$

Therefore, the conjugate expression is

$$
\phi=-\frac{1}{2} r^{2} \frac{\sin 2 \theta}{\cos 2 \beta}-\alpha^{2} \sum_{n=0}^{\infty} A_{-i n+1}\left(\frac{r}{a}\right)^{(2 n+1) \pi / 2 \beta} \sin \frac{(2 n+1) \pi \theta}{2 \beta} .
$$

Let $x^{\prime}, y^{\prime}$ be the rectangular co-ordinates, the axes of which are parallel to the axes of $x$ and $y$, and the origin of which is at the centre of the bounding circle of the sector. It is obvious that the stress due to torsion is independent of the position of axes, so long as they remain parallel. Accordingly, in torsion problem, the origin of co-ordinates can be selected at any point on the cross-section. And, moreover, the stress components, $X_{z}=\mu \tau(\partial \phi / \partial x$ $-y), \quad Y_{z}=\mu \tau(\partial \phi / \partial y+x)$, keep the same form irrespective of the position of the origin. Hence, if we transform the origin to the centre of the circle, the stress components referring to the axes $x^{\prime}$ and $y^{\prime}$ may be written, in virtue of (18), as follows:-

$$
X_{z}^{\prime}=\mu \tau\left(\frac{\partial \phi}{\partial x^{\prime}}-y^{\prime}\right)-\frac{W}{2(1+\sigma) I}\left\{\frac{\partial \chi^{\prime}}{\partial x^{\prime}}+(2+\sigma)\left(x^{\prime}-k\right) y^{\prime}\right\},
$$

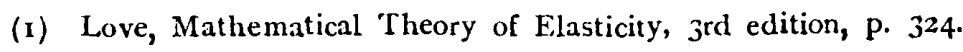




$$
Y_{z}=\mu \tau\left(\frac{\partial \phi}{\partial y^{\prime}}+x^{\prime}\right)-\frac{W}{2(\mathrm{I}+\sigma) P}\left\{\frac{\partial \chi^{\prime}}{\partial y^{\prime}}+\left(\mathrm{I}-\frac{1}{2} \sigma\right)\left(x^{\prime}-k\right)^{2}+\frac{1}{2} \sigma y^{\prime \prime}\right\}
$$

Transforming again to the polar co-ordinates and substituting (I6) and (22) in these equations, we have

$$
\begin{aligned}
& X_{z}=-\mu \tau\left[\left(\frac{\mathrm{I}}{\cos 2 \beta}+\mathrm{I}\right) r \sin \theta\right. \\
& \left.+\frac{\pi a}{2 \beta} \sum_{n=0}^{\infty} A_{2 n+1}(2 n+1)\left(\frac{r}{a}\right)^{(2, i+1) \pi / 2 \beta-1} \sin \left\{\frac{(2 n+1) \pi}{2 \beta}-1\right\} \theta\right] \\
& -\frac{W}{2(\mathrm{I}+\sigma) I^{\prime}}\left[-\sigma\left(\frac{\mathrm{I}}{\cos 2 \beta}+\mathrm{I}\right) k r \sin \theta\right. \\
& +\left\{\left(\frac{1}{4}+\frac{1}{2} \sigma\right)-\left(\frac{1}{4}-\frac{1}{2} \sigma\right) \frac{\cos \beta}{\cos 3 \beta}\right\} r^{2} \sin 2 \theta \\
& \left.+8 a^{2} \beta \sum_{n=0}^{\infty} B_{3_{i l+1}}(2 n+\mathrm{I})\left(\frac{\gamma}{a}\right)^{(2 n+1) \pi / 2 \beta-1} \sin \left\{\frac{(2 n+\mathrm{I}) \pi}{2 \beta}-\mathrm{I}\right\} \theta\right], \\
& Y_{z}=-\mu \tau \Gamma\left(\frac{\mathrm{I}}{\cos 2 \beta}-\mathrm{I}\right) r \cos \theta \\
& \left.+\frac{\pi \alpha}{2 \beta} \sum_{n=0}^{\infty} A_{2 n+1}(2 n+\mathrm{I})\left(\frac{r}{\alpha}\right)^{(2 n+1) \pi / 2 \beta-1} \cos \left\{\frac{(2 n+\mathrm{I}) \pi}{2 \beta}-\mathrm{I}\right\} \theta\right] \\
& -\frac{W}{2(\mathrm{I}+\sigma) L^{\prime}}\left[\frac{1}{2} r^{2}-\sigma\left(\frac{\mathrm{I}}{\cos 2 \beta}-\mathrm{I}\right) k r \cos \theta\right. \\
& -\left\{\left(\frac{1}{4}+\frac{1}{2} \sigma\right)+\left(\frac{1}{4}-\frac{1}{2} \sigma\right) \frac{\cos \beta}{\cos 3 \beta}\right\} r^{2} \cos 2 \theta \\
& \left.+8 a^{2} \beta \sum_{n=0}^{\infty} B_{2 n+1}(2 n+\mathrm{I})\left(\frac{r}{a}\right)^{(2 n+1) \pi / 2 \beta-1} \cos \left\{\frac{(2 n+\mathrm{I}) \pi}{2 \beta}-\mathrm{I}\right\} \theta\right] .
\end{aligned}
$$

where $A_{2 n+1}$ and $B_{2 n+1}$ are given by (2I) and (17) respectively.

When $\beta=\pi / 6, \pi / 4, \pi / 2,3 \pi / 4$, or $5 \pi / 6$, some of the coefficients of the terms in the above equations become indeterminate. But we may easily show that all of those coefficients have finite limits. Hence the results given by the equations are definite for all values 
of $\beta$ between $o$ and $\pi$.

If $\pi / 2 \beta-1>0$ or $\beta<\pi / 2$, then all terms in the equations (23) vanish, when $r=0$. Therefore, the shearing stress at the corner of the sector, where the two radial boundaries meet, is zero.

If $\pi / 2 \beta-I<0$ or $\beta>\pi / 2$, then the terms in (23) excepting the first terms of the infinite series become very small when $r$ is very small. Hence, in this case, we have approximately

$$
\left.\begin{array}{l}
X_{z}=-\left\{\frac{\pi \mu \tau a}{2 \beta} A_{1}+\frac{4 W a^{2} \beta}{(\mathrm{I}+\sigma) P^{\prime}} B_{1}\right\}\left(\frac{r}{a}\right)^{\pi / 2 \beta-1} \sin \left(\frac{\pi}{2 \beta}-\mathrm{I}\right) \theta, \\
Y_{z}=-\left\{\frac{\pi \mu \tau a}{2 \beta} A_{1}+\frac{4 W a^{2} \beta}{(\mathrm{I}+\sigma) I^{\prime}} B_{1}\right\}\left(\frac{r}{a}\right)^{\pi / 2,3-1} \cos \left(\frac{\pi}{2 \beta}-\mathrm{I}\right) \theta
\end{array}\right\}
$$

where $A_{1}$ and $B_{1}$ are the values of $A_{2 t+1}$ and $B_{2, t+1}$ when $n=0$. As explained before, the constant $\tau$ is to be so adjusted that the sum of the two couples given by (I9) and (20) vanishes. Hence, the expression within the large brackets of the equations (24) will not, in general, vanish. And, as $(r / a)^{\pi / 2,3-1}$ in the above equations becomes very great when $r$ is very small, the shearing stresses become very great near the centre of the circle.

Hence, if the corner at the centre of the bounding circle of the sector is projecting outwards, the shearing stress at such a sharp corner is zero, and, if the corner is projecting inwards, the shearing stress near such a sharp corner becomes very great. It is only by the yielding of materials that such a concentration of stresses is relieved in actual beams,

If $\pi / 2 \beta-\mathrm{I}=0$ or $\beta=\pi / 2$, then the equations (23) become

$$
\begin{aligned}
& X_{z}=0 \\
& Y_{z}=-\left\{\frac{\pi \mu \tau \alpha}{2 \beta} A_{1}+\frac{4 W \alpha^{2} \beta}{(\mathrm{I}+\sigma) l^{\prime}} B_{1}\right\},
\end{aligned}
$$

when $r=0$. Thus, when the section is semi-circular, the shearing 
stress at the middle of the diametrical vertical boundary is parallel to this boundary and has a finite value given by the above equation.

If $\beta=\pi$, the section is a circle which has a horizontal crack extending from the centre to the circular boundary, In this case, the shearing stress near the end of such a crack becomes very severe.

Now, let the resultant shearing stress of $X_{z}$ and $Y_{z}$ make an angle $\alpha$ with the axis of $x$, then we have

$$
\tan \alpha=\frac{Y_{z}}{X_{z}}
$$

If $\beta>\pi / 2$, we have, from (24),

$$
\tan \alpha=\cot \left(\frac{\pi}{2 \beta}-1\right) \theta
$$

when $r$ is very small. Therefore,

$$
\alpha=\frac{\pi}{2}-\left(\frac{\pi}{2 \beta}-\mathrm{I}\right) \theta
$$

which gives the directions of the resultant shearing stresses near the corner projecting inwards.

Fig. 6 shows the directions of the shearing stresses on the cross-section near the corner projecting inwards when $\beta=3 \pi / 4$. The stresses are very great.

It is well known that in a twisted shaft, if the boundary has a sharp re-entrant, the shearing stress near the corner is very great, and, if the boundary has a sharp projection, the shearing stress is zero at such a projection. We have obtained similar results for the bending of a beam having a sharp corner in the cross-section, which is not on the vertical symmetrical axis of the section. It will easily be seen from the equations (24), that this is partly due to the twisting, and partly to the bending of the beam. 


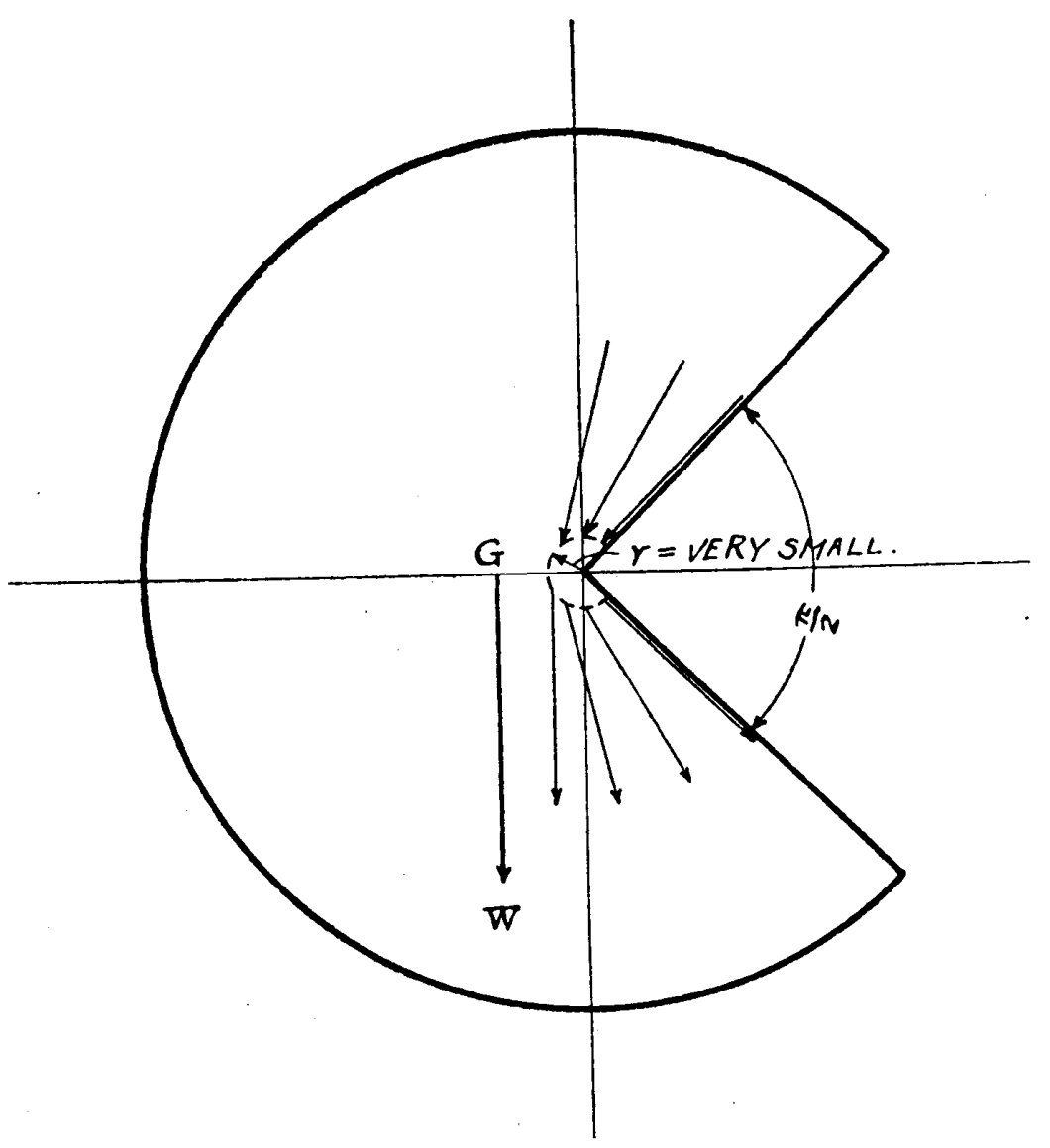

lig. 6. Directions of Shearing Stresses near the Corner.

In applying forces to the cross-section at the free end of a beam, which are equivalent to a vertical load $W$ acting on a line not passing through the centroid of the section, more or less twist is associated according to the position of the line of application of the load. It is evident, however, that we may choose a line of application in such a position that the load p:oduces no twist. Then the terms containing $\tau$ in (24) will vanish. A glance on the equations (24) will show that, even in this case, the shearing stress 
near the sharp corner projecting inwards may still be very large.

The state of concentration of the shearing stresses near the corner of a sharp re-entrant will be seen from Fig. 7, in which the

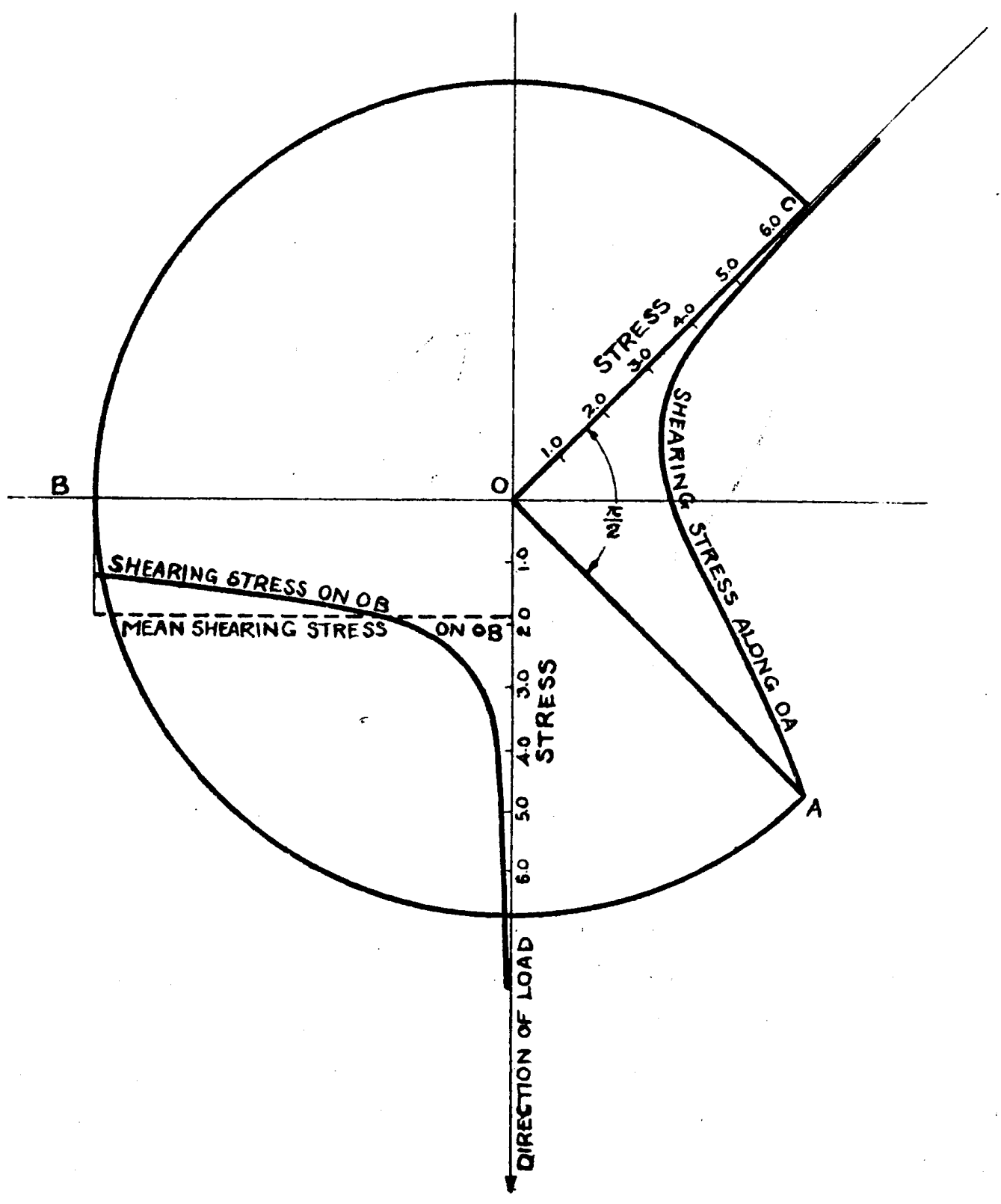

1iig. 7. Distributions of Shearing Stresses. 
shearing stresses on the straight boundary and on the neutral axis are shown. They are worked out from (23) for the section of $\beta=3 \pi / 4$, when the load is applied in such a position that the beam is not subjected to any twist, i. e., when $\tau=0$. The stresses are given in terms of the mean shearing stress taken over the area of the cross-section, and Poisson's ratio is taken to be $\mathrm{I} / 4$.

\section{Part II. Experiments.}

\section{r. Expcriment with India-Rubber Model.}

In Part I, it has mathematically been shown that the shearing stresses in a beam are very severe at the corner of a sharp re-entrant in the cross-section. This fact can be seen experimentally with an india-rubber model. The cross-section of the model used was "I" shaped, having the dimensions as shown in Fig. 8. It was cut out by a milling machine from a rectangular solid block of india-rubber, about $56 \mathrm{~cm}$ long, 5.4 $\mathrm{cm}$ deep, and $2.6 \mathrm{~cm}$ broad. One end of this beam was clamped on a rigid table, and a load of $4 \mathrm{~kg}$ was applied at a distance of $12 \mathrm{~cm}$ from the fixed end. The arrangement of loading the beam is as shown in Fig. 9. The web at the clamped part was, as shown in the figure, stiffened by two wooden planks to prevent buckling.

In virtue of equality of shearing stresses in two directions, that on a cross-section at a point on its boundary

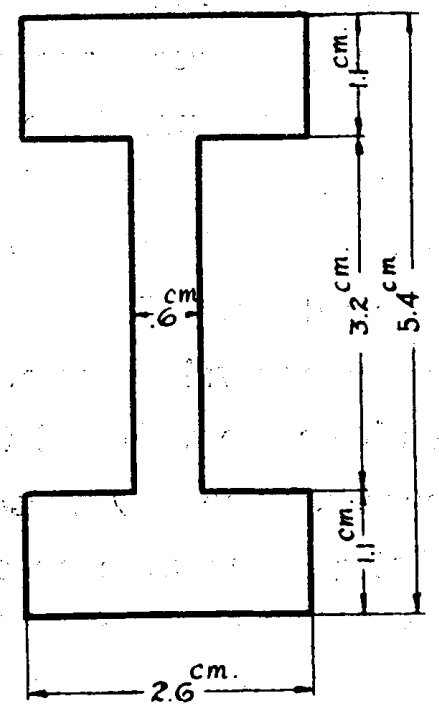

Fig. 8. Section of Indialiubber Model. 

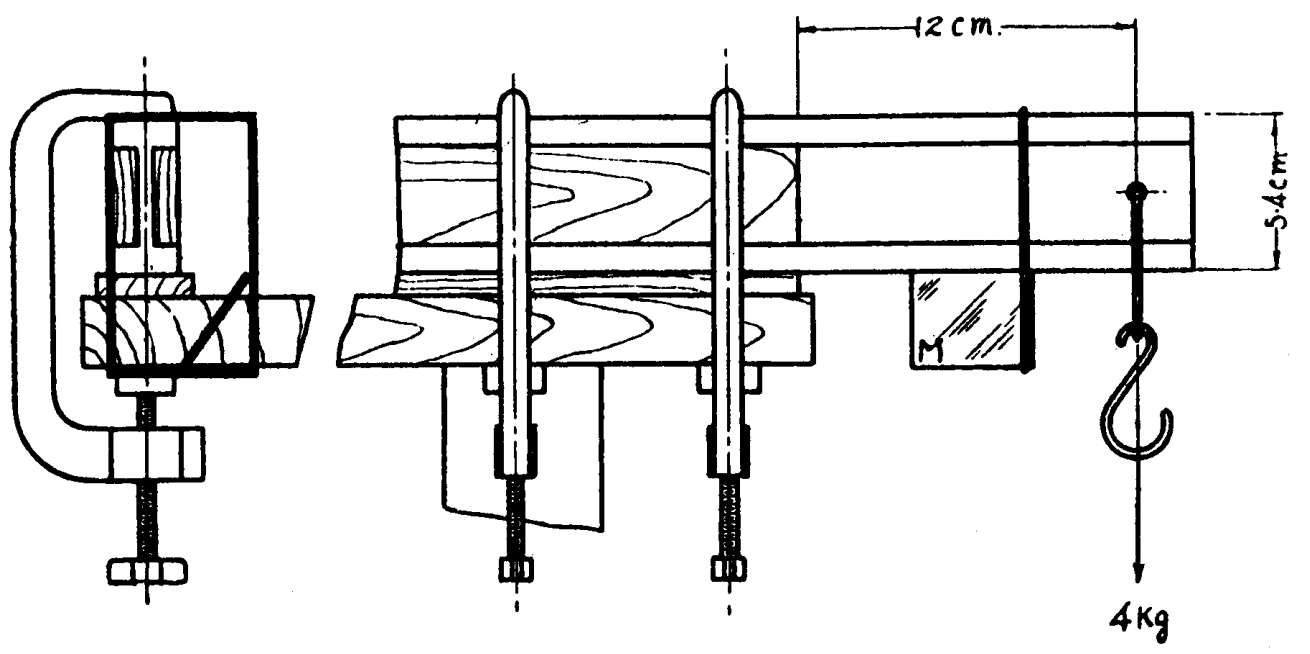

Fig. 9. Arrangement of Ioading India-Rubler Model.

is shown by the shearing strains corresponding to the longitudinal axis and the axis perpendicular to it on the surface of the beam. Therefore, if we observe the shearing strains corresponding to these axes on the surface of the web and on the inner surface of the flange, we can find the shearing stresses on the cross-section at its boundary, provided the elastic constant of the india-rubber used is known. Thus the stress-concentration, if exists, can easily be found.

To measure these strains, a number of single fibre of black silk thread for embroidary use were laid on the surface of the web and on the inner surface of the flange, fixing them by a coat of thin gelatin. They were placed both longitudinally and transversely at an interval of $2 \mathrm{~mm}$. An additional longitudinal fibre was sticked both on the web and the flange at a distance of $\mathrm{I} \mathrm{mm}$ from the corner. The transverse fibres were 10 in number and so placed that 5 fibres were on each side of the section midway between the fixed end and the loaded section. Before and after loading, these parts of the web and the flange were photographed. The camera was placed at a proper distance from the surface of the web, and the requisite part of the web was photographed directly. In taking 
the photographs of the inner surface of the flange, a mirror $M$ was placed at an angle about 45 degrees to the surface of the flange. In order to keep the magnifications of the photographs always the same, the distance between the camera and the surface of the flange was kept constant by attaching the mirror to the model as shown in Fig. 9.

The photographs of the original and strained states are shown in Figs. 10 to $13, \mathrm{Pl}$. 8. The negatives of these were projected on a wall by a projector, giving a figure about ro times the actual size of the model; the measurements were taken therefrom, and the shearing strains at several points were calculated. As the shearing strains are practically equal along a longitudinal line, the means of the observed strains on the same longitudinal lines were taken. The shearing strains observed at several points are given in Tables $I$ and 2.

\section{Table 1.}

Observed Shearing Strains on the Surface of the Web and the Corresponding Shearing Stresses on the

Cross-Section at its Boundary.

\begin{tabular}{|c|c|c|}
\hline Distance from Corner in mm. & Shearing Strain. & Shearing Stress in $\mathrm{kg} / \mathrm{cm}^{2}$. \\
\hline 0.5 & 0.076 & 2.03 \\
1.5 & 0.058 & 1.55 \\
3.0 & 0.053 & 1.42 \\
5.0 & $0.05 \mathrm{I}$ & 1.36 \\
7.0 & 0.051 & 1.36 \\
9.0 & 0.041 & 1.10 \\
11.0 & 0.031 & 0.83 \\
13.0 & 0.030 & 0.80 \\
15.0 & 0.041 & 1.10 \\
\hline
\end{tabular}




\section{Table 2.}

Observed Shearing Strains on the Inner Surface of the Flange and the Corresponding Shearing Stresses on the Cross-Section at its Boundary.

\begin{tabular}{|c|c|c|}
\hline Distance from Corner in mm. & Shearing Strain. & Shearing Stress in $\mathrm{kg} / \mathrm{cm}^{2}$. \\
\hline 0.5 & $0.06 \mathrm{I}$ & 1.63 \\
1.5 & 0.050 & 1.34 \\
3.0 & 0.035 & 0.94 \\
5.0 & 0.025 & 0.67 \\
7.0 & 0.018 & 0.48 \\
\hline
\end{tabular}

For the calculation of the shearing stresses, we must find the modulus of rigidity of the india-rubber used. A test piece, about $20 \mathrm{~cm}$ long, $26.6 \mathrm{~mm}$ broad, and $5.8 \mathrm{~mm}$ thick, cut out from the web of the model, was tested under tension, and the elongations on the gauge length of $10 \mathrm{~cm}$ and the contractions in the breadth were measured. They are given in Table 3, and also shown diagrammatically in Fig. I4. The load-elongation curve was not represented by a straight line. The maximum principal stress in the beam under the present experiment is estimated to be about 2 $\mathrm{kg} / \mathrm{cm}^{2}$, without regarding stress-concentration, and, fortunately, up to this stress, the load-elongation curve is nearly a straight line, and therefrom we can take $E=78.4 \mathrm{~kg} / \mathrm{cm}^{2}$. From the observed elongations and contractions, Poisson's ratio, $\sigma$, was calculated. It varies from 0.5 to 0.46 as given in Table 3. Assuming this is 0.48 , we have the modulus of rigidity

$$
\mu=\frac{E}{2(\mathrm{I}+\sigma)}=26.7 \mathrm{~kg} / \mathrm{cm}^{2} \text {. }
$$

Using this value, we get the shearing stresses at several points, which are given in Tables $I$ and 2, and their distributions are 
shown in Fig. I5. In this figure, the distribution of the mean. shearing stresses in the model taken across the horizontal breadth calculated from usual formula is shown by a broken line. It will be seen from the figure that, at the corner, the shearing stresses

\section{Table 3.}

Tension Test of India-Rubber.

$$
\begin{aligned}
& \text { Breacth }=26.6 \mathrm{~mm}, \\
& \text { Thickness }=5.8 \mathrm{~m} / \mathrm{m}, \\
& \text { (iauge length }=100 \mathrm{~mm} .
\end{aligned}
$$

\begin{tabular}{|c|c|c|c|c|c|c|}
\hline \multirow{2}{*}{ Iond in $\mathrm{gr}$. } & \multirow{2}{*}{$\begin{array}{c}\text { Tension } \\
\text { in } \mathrm{kg} / \mathrm{cm}^{2} \text {. }\end{array}$} & \multicolumn{2}{|c|}{ Elo gation. } & \multicolumn{2}{|c|}{ Contraction. } & \multirow{2}{*}{ Poisson's Ratio. } \\
\hline & & $\left(\begin{array}{c}\text { In } \mathrm{mm} \\
(\mathrm{On} 100 \mathrm{~mm})\end{array}\right.$ & In $\%$ & $\begin{array}{c}\text { In } \mathrm{mm} . \\
\text { (In breadth) }\end{array}$ & In $\%$. & \\
\hline 500 & 0.324 & 0.35 & o. 35 & 0047 & 0.176 & 0.50 \\
\hline $1, \infty 00$ & 0.649 & 0.77 & 0.77 & 0.098 & 0.368 & 0.48 \\
\hline 1,500 & 0.973 & I. 20 & 1.20 & 0.152 & $0.57 \mathrm{I}$ & 0.48 \\
\hline 2,000 & 1.297 & I. 64 & 1.64 & 0.207 & 0.777 & 0.47 \\
\hline 2,500 & 1.621 & 2.10 & 2.10 & 0.264 & 0.992 & 0.47 \\
\hline 3,000 & 1.946 & 2.56 & 2.56 & 0.324 & 1.22 & 0.48 \\
\hline 3,500 & 2.27 & 3.04 & 304 & $0.3^{81}$ & 1.43 & 047 \\
\hline $4, \infty 00$ & 2.59 & $3 \cdot 52$ & $3 \cdot 52$ & 0.437 & 1.64 & 0.47 \\
\hline 4,500 & 2.92 & 4.02 & 4.02 & 0.492 & 1.85 & 0.46 \\
\hline
\end{tabular}

experimentally found are severer than those given by the usual formula both on the surfaces of the web and the flange, and, also, that the distribution on the inner surface of the flange is very similar to that on the radial boundary of the sector shown in Fig. 7, which is found theoretically. Therefore, from the result of this experiment, we may conclude that the stress-concentration at the corner of a sharp re-entrant mathematically obtained in Part I, will really exist in beams having a corner. 


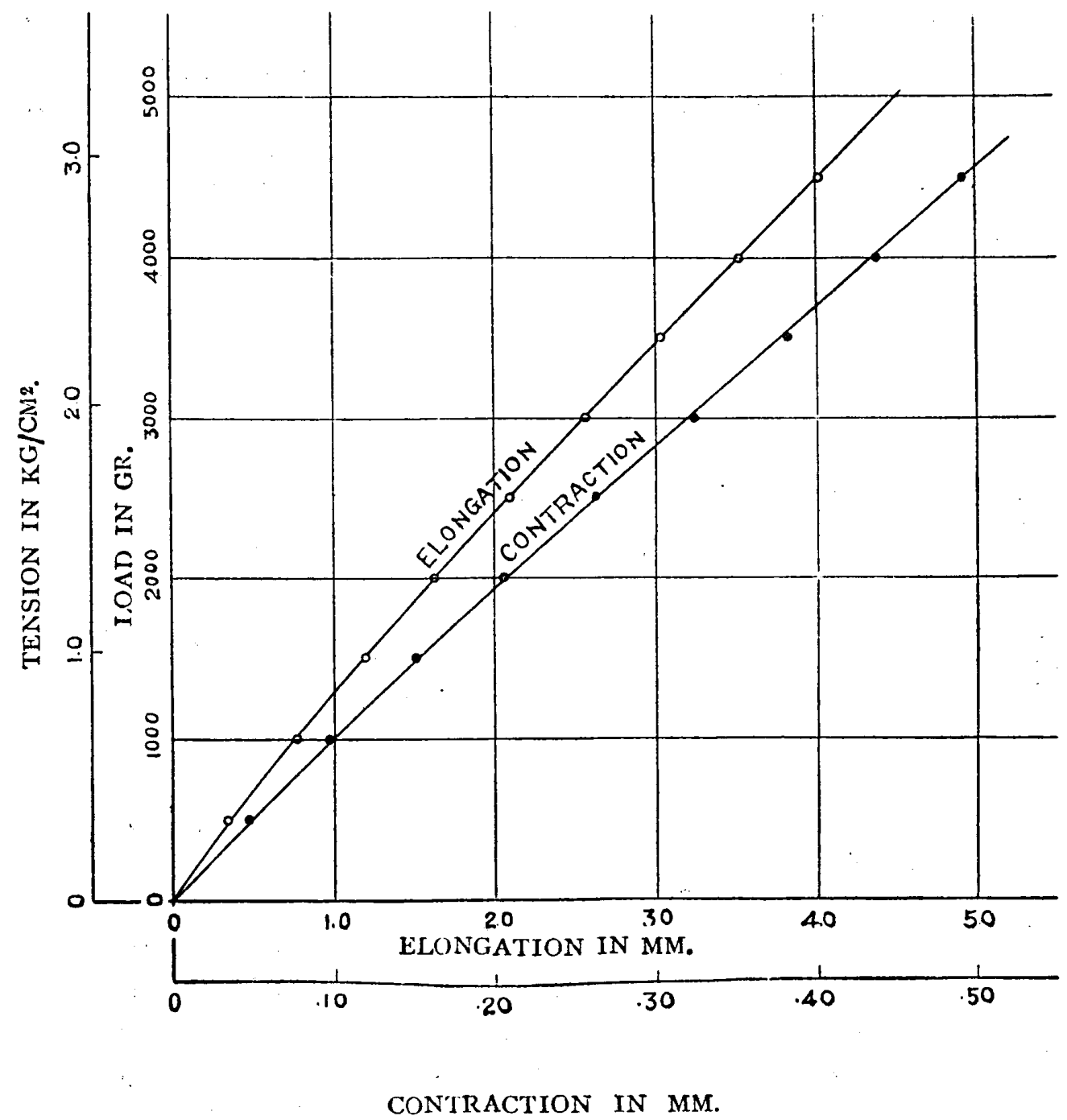

Fig. 14. Load-Deformation Curves of India-Rubber Specimen under Tension.

In Fig. 15, it will be noticed that, near the neutral axis, the observed shearing stresses are less than the mean shearing stresses calculated from the practical formula. At this part, the shearing stresses would be nearly uniformly distributed across the breadth, and, therefore, the above two values ought to coincide. The difference is too large to be attributed to the inaccuracy of the observations and the error involved in estimating the elastic constants. It has been found later that, by a microscope examination, 
Shearing Stresses in Beans of Certain Cross-Sectons.

some silk fibres near the neutral axis have slipped at the points of crossing each other. This was due to imperfect coating of

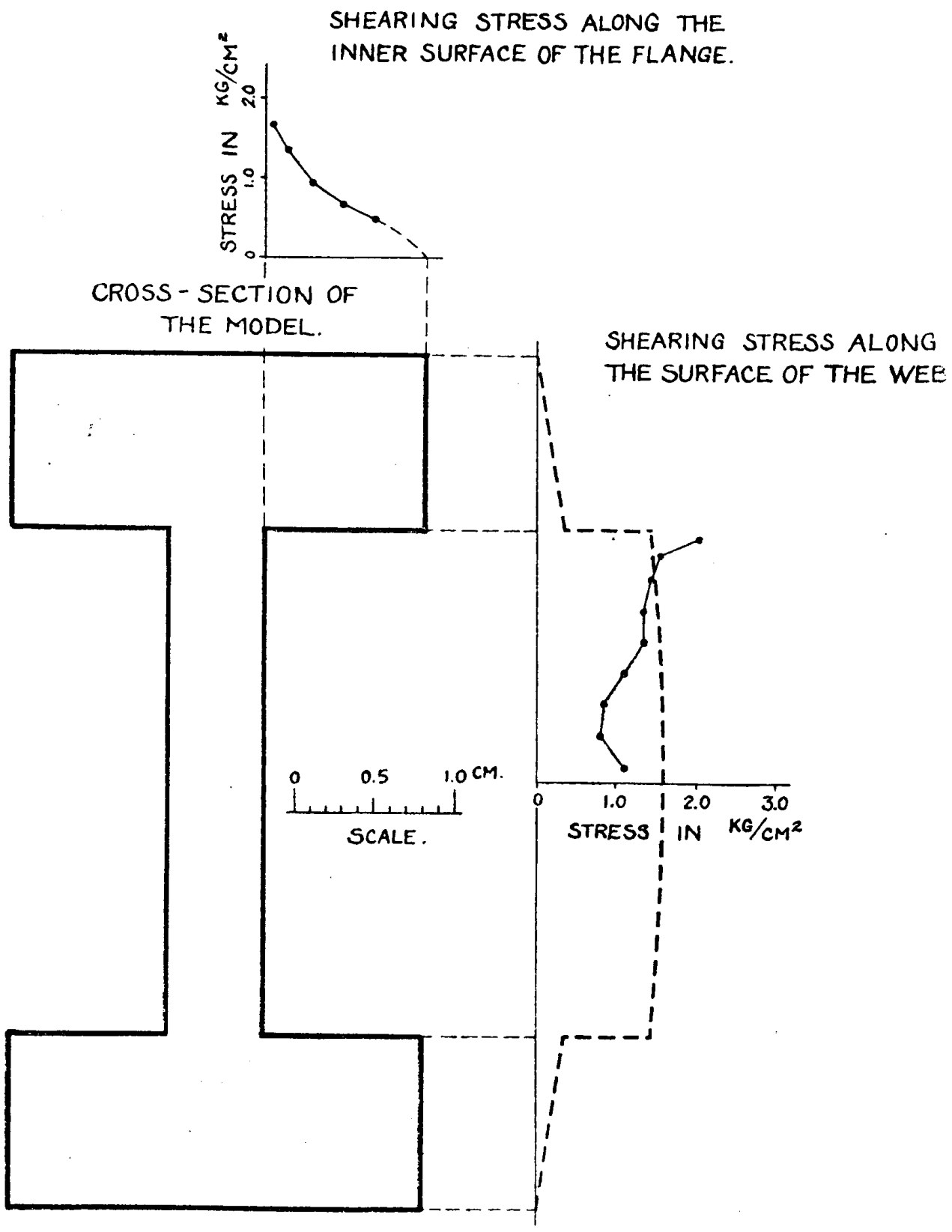

Fig. 15. - Distributions of Shearing Stresses on theC ross-Section of the India-Rubber Mocel. 
gelatin on the fibres, but, on the other part where they were well coated, the slipping could not be observed. The great difference between the observed and calculated shearing stresses near the neutral axis will likely be due to this slipping. Anyhow, from the general feature of the diagrams of the observed stresses, it can be concluded that the stress-concentration does exist actually at a corner.

\section{Bending Tests of Teak Beams.}

The existence of stress-concentration cannot generally be evidenced by a statical breaking test, because, in applying a steadily increasing load to the specimen, yielding takes place on that part which is subjected to the stress-concentration, to make the distribution of stresses fairly uniform. Consequently, the effect of the stress-concentration on the ultimate strength is not so conspicuous as is expected at first sight. Nevertheless, the stress-concentration does affect the ultimate strength to a certain extent as is shown in the experiment described below.

“ $A$ "

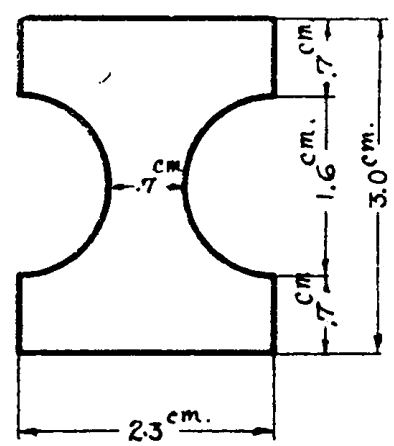

"p"

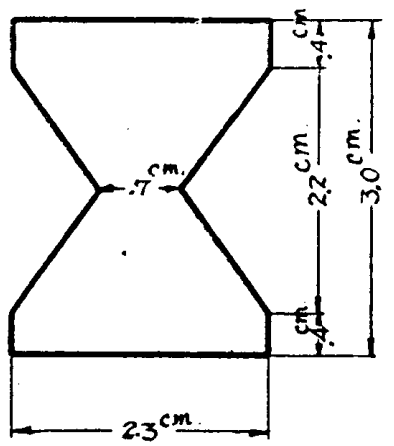

" $X$ "

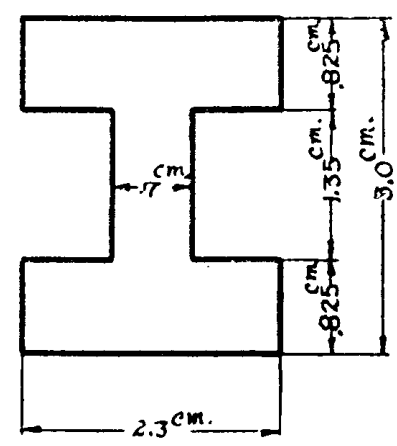

Fig. 16. Sections of Teak Beams.

The specimens used in the experiment were teak beams of 30 cm long, having three different forms of cross-section as shown in 
Fig. I6. They were supported at a span of $20 \mathrm{~cm}$, and loaded at the centre of the span. The section marked " $A$ " had no sharp re-entrant, while that marked " $p$ " had a sharp re-entrant at the neutral axis, and that marked " $X$ " was of " $I$ " form. As will be seen in Fig. 16 and Table 4, these sections had the same depths, and not only the moments of inertia of the sections about the neutral axis but also the moments of area about the neutral axis and the breadths at the neutral axis were practically equal.

Table 4.

Areas, Moments, and Moments of Inertia of Sections of Teak Beams.

\begin{tabular}{|c|c|c|c|c|}
\hline Section. & $\begin{array}{c}\text { Area } \\
\text { in cm }\end{array}$ & $\begin{array}{c}\text { Moment of } \\
\text { Inertia } \\
\text { in } \mathrm{cm}^{4} .\end{array}$ & \multicolumn{2}{|c|}{ Moment of Area about N. A. in $\mathrm{cm}^{3}}$. \\
\hline " $A "$ & 4.89 & 4.85 & 2.25 & - \\
" $P$ " & 5.14 & 4.82 & 2.26 & For Area above N. A. Areil of One Flange. \\
" $X "$ & 4.74 & 4.85 & 2.22 & 2.06 \\
\hline
\end{tabular}

Therefore, with the same load the beams of these three different sections are subjected to the same normal stress at extreme fibres, and the same mean shearing stress across the breadth at the neutral axis. Accordingly, the relative ultimate strength of these beams which is influenced by the form of the sections can directly be compared by the breaking load.

The grains of the specimens ran longitudinally, and the annual rings were taken parallel to the vertical axis of the cross-section. The sections were so determined that the specimens are stronger against the bending moment than against the shearing force, and they were expected to fail by shear. Actually, most of them failed 
by shear as anticipated, excepting a few cases, where they failed by tension at the bottom fibres or by crushing at the point of application of the load.

The results of the tests are given in Tables 5 to 7 . In these tables, the breaking load and the mean shearing stress across the breadth at the neutral axis of all specimens are given, and, in addition to them, that across the breadth at the heel of the web is given for the specimens of "I" section. The planes on which the failure took place together with the manners of failure are also given in the tables.

As is well known, the strength of the timber depends on the weight and the moisture content. So that, after the tests, the specimens were dried in a drying chamber and the moisture contents were measured. The weights per unit volume and the percentages of moisture are also given in Tables 5 to 7 . The latter varied from $I_{5}$ to $30 \%$, and the average value was about $17 \%$.

Taking the weight per unit volume as the abscissa, and the breaking load as the ordinate, the results of the tests are plotted in Fig. 17. Assuming the relation between them to be linear, straight lines were determined for each sections by the method of least squares, and they are drawn in the figure. In determining these straight lines, the cases, in which the specimen's failure was not by shearing, were not taken into account. It will be seen from the diagiams that the specimens of the section marked " $P$ " failed by a load lower than that by which those of the section marked " $A$ " failed. Moreover, it will be noticed from Table 6 that, with the section " $P$ ", the majority of the shearing-off took place at or near the neutral surface. For an illustration, the photographs of the specimens, $P$ Io and $P_{16} 6$, are shown in Fig. $18, \mathrm{Pl}$. 8. With the section " $A$ ", although the positions of the plane of 
shearing-off were not far from the neutral surface, yet they were quite indefinite, as will be seen in Table 5 and the photographs of the specimens $A$ I and $A_{5}$ in Fig. I8. These results may suggest the existence of stress-concentration at a sharp re-entrant in the cross-section.

Table. 5 .

Results of Bending Tests of Teak Beams having the Section marked " $A$ ".

Form of Section : 5

\begin{tabular}{|c|c|c|c|c|c|}
\hline $\begin{array}{c}\text { No. of } \\
\text { Specimen. }\end{array}$ & $\begin{array}{l}\text { Weight in } \\
\mathrm{gr} / \mathrm{cm}^{3}\end{array}$ & $\begin{array}{c}\text { Moisture } \\
\% .\end{array}$ & $\begin{array}{l}\text { Max. Ioad } \\
\text { in } \mathrm{kg} \cdot\end{array}$ & $\begin{array}{l}\text { Shearing Stress } \\
\text { at N. A. } \\
\text { in } \mathrm{kg} / \mathrm{cm}^{2} .\end{array}$ & $\begin{array}{l}\text { Manner of } \\
\text { iailure. }\end{array}$ \\
\hline$A \quad$ I & .542 & 14.7 & 415 & 275 & Shearins ${ }^{\circ}$ \\
\hline$A=$ & .616 & 16.4 & $4^{85}$ & 322 & Shearing* \\
\hline$A \quad 3$ & .531 & 149 & 370 & 245 & Tension \\
\hline$A \quad 4$ & .617 & 15.1 & 469 & 3II & Shearing* \\
\hline$A \quad 5$ & .626 & 20.2 & 385 & 255 & She aring*. \\
\hline$A \quad 6$ & .515 & 16.6 & 312 & 207 & Tensicn \\
\hline$A \quad 7$ & .623 & 15.8 & 446 & 296 & Shearing* \\
\hline$A \quad 8$ & .604 & 17.8 & 386 & 256 & Shearing* \\
\hline$A \quad 9$ & .571 & 16.5 & 374 & 248 & Crushing \& Tension \\
\hline & .529 & 15.4 & 368 & 244 & Tension \\
\hline$A \mathrm{II}$ & $.53 \mathrm{I}$ & 14.7 & 354 & 235 & Crushing \& Tension \\
\hline & .613 & 17.9 & 390 & 259 & Crushing \& Tension \\
\hline$A \mathbf{I} 3$ & .561 & 25.2 & 300 & 199 & Tension \\
\hline$A \mathbf{1 4}$ & $.66 \mathrm{r}$ & 27.2 & 369 & 245 & Shearing ${ }^{\circ}$ \\
\hline$A 15$ & .580 & 16.5 & 409 & 271 & Shearing* \\
\hline$A 16$ & $.54 \mathrm{I}$ & 25.2 & 291 & 193 & Shearing ${ }^{\circ}$ \\
\hline$A 17$ & .592 & I8. 1 & 380 & 252 & Shearirg ${ }^{\circ}$ \\
\hline & .594 & IS.2 & 378 & 251 & Shearing ${ }^{\circ}$ \\
\hline
\end{tabular}

- Plane of shearing-off nearly on the neutral surface,

* Plane of shearing-off not on the neutral surface. 
Table. 6.

Results of Bending Tests of Teak Beams having the Section marked " $P$ ".

Form of Section: 8

\begin{tabular}{|c|c|c|c|c|c|}
\hline $\begin{array}{c}\text { No. of } \\
\text { Specimen. }\end{array}$ & $\begin{array}{l}\text { Weight in } \\
\mathrm{gr} / \mathrm{cm}^{3} \text {. }\end{array}$ & $\begin{array}{c}\text { Moisture } \\
\% .\end{array}$ & $\begin{array}{l}\text { Max. Joad } \\
\text { in kg. }\end{array}$ & $\begin{array}{l}\text { Shearing Stress } \\
\text { at } \mathrm{N} \text {. A. } \\
\text { in } \mathrm{kg} / \mathrm{cm}^{2} \text {. }\end{array}$ & $\begin{array}{c}\text { Manner of } \\
\text { Failure. }\end{array}$ \\
\hline$P \quad \mathrm{I}$ & .639 & 15.2 & 490 & 328 & Shearing $^{\circ}$ \\
\hline$P \quad 2$ & .648 & I 5.9 & 470 & 315 & Shearing* \\
\hline$P \quad 3$ & .514 & 15.3 & 349 & 234 & Shearing $^{\circ}$ \\
\hline $\begin{array}{l}P \quad 4 \\
\end{array}$ & .656 & IS.I & 414 & 277 & Shearing* \\
\hline$P \quad 5$ & .609 & 15.4 & 419 & 281 & Shearing $^{\circ}$ \\
\hline$P 6$ & .519 & 14.8 & 349 & 234 & Tension \\
\hline$P 7$ & .626 & 16.7 & 453 & 304 & Sheiring ${ }^{\circ}$ \\
\hline$P \quad \mathrm{~S}$ & .525 & 15.2 & 375 & $25 \mathrm{I}$ & Shearing ${ }^{2}$ \\
\hline$P \quad 9$ & .575 & 21.5 & 321 & 215 & Shearing* \\
\hline$P$ Iо & .542 & 17.0 & 345 & 231 & Shearing* \\
\hline$P$ II & .614 & I6.I & 406 & 272 & Tension \\
\hline$P_{12}$ & .623 & 23.8 & 350 & 235 & Shearing $^{\circ}$ \\
\hline$P_{13}$ & $.53^{8}$ & 21.1 & 290 & I 94 & Shearing $^{\circ}$ \\
\hline$P_{14}$ & .574 & 29.7 & 263 & 176 & Shear $\mathrm{ng}^{\circ}$ \\
\hline$P \mathbf{1 5}$ & .641 & 28.4 & 346 & 232 & Shearing* \\
\hline$P 16$ & .576 & 20.5 & 332 & 222 & Shearing $^{\circ}$ \\
\hline$P 17$ & .560 & 23.1 & 305 & 204 & Shearing ${ }^{\circ}$ \\
\hline$P$ IS & .544 & 14.9 & 341 & 228 & Shearing $^{\circ}$ \\
\hline
\end{tabular}

- Plane of shearing-off exactly on the neutral surface.

* Plane of shearing-off mainly on the neutral surface, and partly deviating from it. 
Shcaring Stresses in Beams of Certain Cross-Sections.

Table. $\%$

Results of Bending Tests of Teak Beams having the Section marked " $X$ ".

Form of Section: 5

\begin{tabular}{|c|c|c|c|c|c|c|}
\hline \multirow{2}{*}{$\begin{array}{l}\text { No. of } \\
\text { Specimen. }\end{array}$} & \multirow{2}{*}{$\begin{array}{l}\text { Weight } \\
\text { in } \mathrm{gr} / \mathrm{cm}^{3} \text {. }\end{array}$} & \multirow{2}{*}{$\begin{array}{c}\text { Moisture } \\
\% .\end{array}$} & \multirow{2}{*}{$\begin{array}{l}\text { Max. Load } \\
\text { in } \mathrm{kg} .\end{array}$} & \multicolumn{2}{|c|}{$\begin{array}{l}\text { Shearing Stress } \\
\text { in } \mathrm{kg} / \mathrm{cm}^{2}\end{array}$} & \multirow{2}{*}{$\begin{array}{l}\text { Ma ner } \\
\text { of } \\
\text { Failure. }\end{array}$} \\
\hline & & & & At N. A. & $\begin{array}{l}\text { At Top or } \\
\text { Bottom of } \\
\text { Web. }\end{array}$ & \\
\hline$X \quad \mathbf{I}$ & .605 & I6. 4 & 404 & 264 & 245 & Shearing ${ }^{\circ}$ \\
\hline$X \quad 2$ & .546 & 14.6 & 355 & 232 & 215 & Shearing $^{\circ}$ \\
\hline $\begin{array}{ll}X & 3\end{array}$ & .616 & 160 & 394 & 258 & 239 & Shearing ${ }^{2}$ \\
\hline$X 4$ & .641 & 18.5 & 405 & 265 & 246 & Crushing \\
\hline$X \quad 5$ & .531 & 14.7 & 343 & 224 & 208 & Shearing ${ }^{\circ}$ \\
\hline$X 6$ & .537 & 16.2 & 324 & 212 & I 97 & Shearing $^{\circ}$ \\
\hline $\begin{array}{ll}X & 7\end{array}$ & .647 & 16.3 & 460 & 301 & 279 & Shearing ${ }^{\circ}$ \\
\hline$X \quad \mathrm{~S}$ & .630 & $15 \cdot 7$ & 437 & 286 & 265 & Shearing $^{\circ}$ \\
\hline$X \quad 9$ & $.66 \mathrm{I}$ & 17.9 & 420 & 275 & 255 & Shearing* \\
\hline$X$ 10 & .592 & 16.9 & 380 & 249 & 231 & Shearing $^{\circ}$ \\
\hline$X$ II & .619 & 16.0 & 394 & $25^{8}$ & 239 & Clushing \\
\hline$X 12$ & .576 & 14.6 & 3 So & 249 & 231 & Tension \\
\hline$X \mathbf{I}_{3}$ & .655 & 206 & 378 & 247 & 229 & Shearing $^{\circ}$ \\
\hline$X 14$ & .665 & 20.3 & 400 & 262 & 243 & Shearing $^{\circ}$ \\
\hline$X 15$ & .561 & I 5.4 & 373 & 244 & 226 & Shearing $^{\circ}$ \\
\hline$X 16$ & .614 & 15.2 & 425 & 278 & 258 & Shearing $^{\circ}$ \\
\hline$X 17$ & .682 & I 9.0 & 409 & 267 & 248 & Shearing $^{\circ}$ \\
\hline$X$ I 8 & .659 & I 8.7 & $3^{8} 9$ & 254 & $23^{6}$ & Shearing $^{\circ}$ \\
\hline
\end{tabular}

- Plane of shexring-off exactly at the ccrner at the top or bottom of the web.

* Plane of shearing-off mainly at the corner at the top or bottom of the web, and partly deviating from it. 
For the section marked " $X$ ", the plane of shearing-off was, in almost all cases, exactiy at the sharp internal corner at the top or bottom of the web, with a single exception, where a part of the plane deviated only a little from the sharp corner. The manners of shearing-off will be seen from the photographs of the specimens $X_{1}$ and $X 9$ in Fig. 18, P1. 8. Comparing the results for the sections " $A$ " and " $X$ ", it will be seen from the diagrams in Fig. I7 that the maximum load for the section " $X$ " is less than that for the section " $A$ ". The mean shearing stress at the top or bottom of the web, where the specimen of the section " $X$ " failed, is $8 \%$ less than the mean shearing stress at the neutral axis. Therefore, if we compare the results with the shearing stress at the part where the failure took place, the value of the stress of the specimen having the section " $X$ ". is still less than that of the section " $A$ ". This may be considered as an evidence of the stress-concentration at the sharp internal corner. Of course, at the heel of the web, the shearing stress is combined with the bending stress, and, consequently, the specimen might fail by a shearing stress less than that at the neutral axis where the bending stress is nil. But the fact that the shearing-off took place nearly always at the plane through the sharp corner, may be another evidence of the stress-concentration at such a place, as was previously explained. In virtue of the above two evidences, we may conclude that the stress-concentration exists at the sharp internal corner at the heel of the web.

By this experiment with the teak beams, it has been confirmed that the shearing stresses at the corner of a sharp re-entrant are severe, and, also, that, even in the statical tests, the ultimate strength of the timber is reduced to a certain extent by the presence of a sharp corner. 


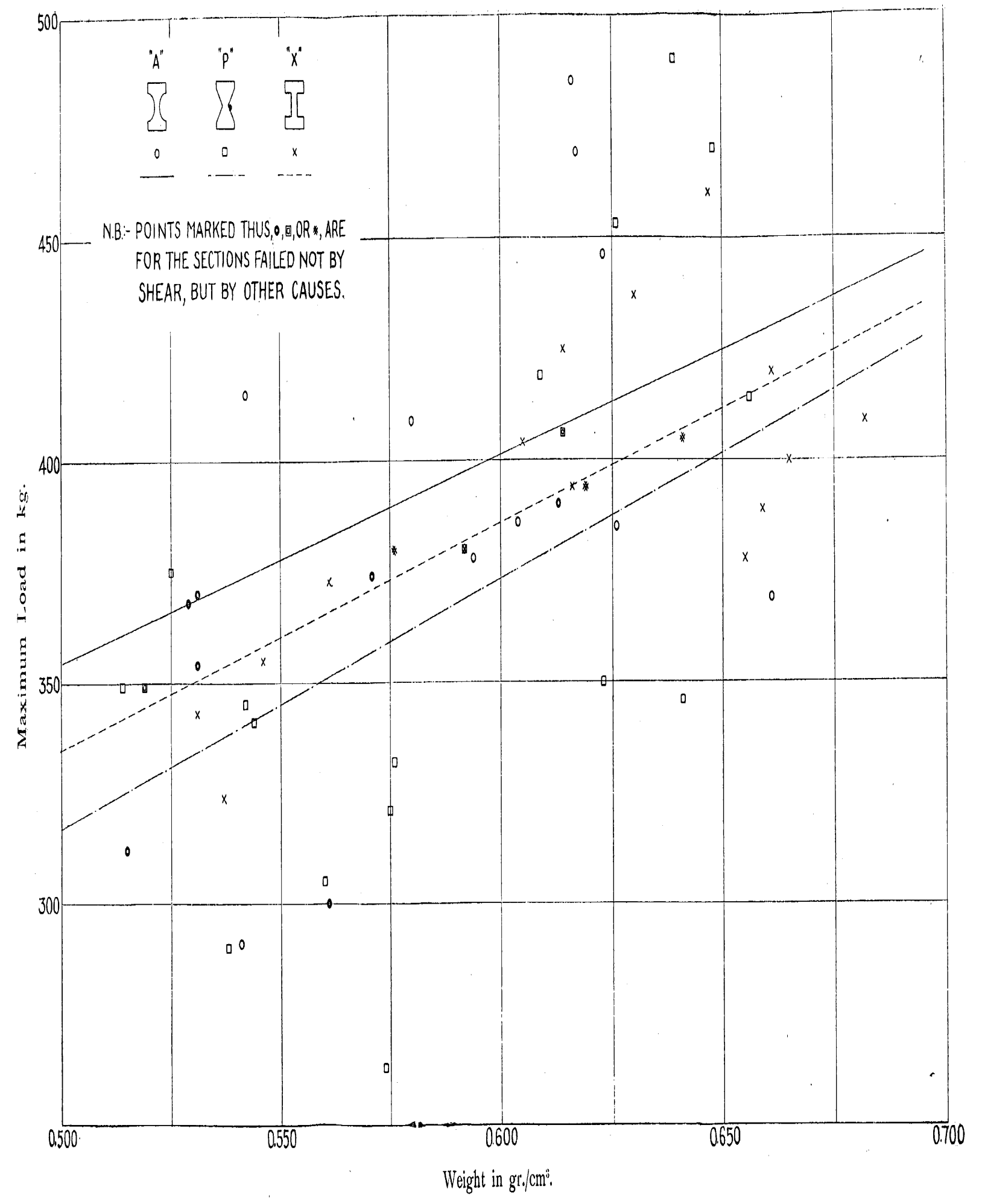

Fig, 17. BENDING TESTS OF 'TEAK BEAMS,

I,AOD.WEIGIIT DIAGRAMS. 


\section{Concluding Remarks.}

The following remarks may be deduced from the foregoing theoretical and experimental investigations:

(I) In the ordinary theory of bending, it is usually assumed that the vertical components of shearing stresses on the crosssection are uniformly distributed across the breadth. At the same time it is generally acknowledged that this assumption is not correct even for some simple sectional forms, such as a rectangle, a circle, or an ellipse. We have seen, from the present investigations, that in some cases the actual distribution of shearing stresses greatly differs from that of the assumption.

It is quite obvious that the shearing stress given by the practical formula is merely the mean value of the vertical components of shearing stresses taken across the breadth.

(2) For a thin hollow cylindrical beam having a symmetrical cross-section about the vertical axis, the resultant shearing stress at any point on the cross-section is in the direction of the tangent at that point to the wall of the beam, and may, with a close approximation, be obtained by the usual practical formula, taking the normal thickness of the wall, instead of the horizontal thickness.

(3) At the end of a crack in the cross-section, the shearing stresses are generally very great. Only in the case where the crack is along the vertical symmetrical axis, the distribution of stresses is not influenced by its presence.

(4) The shearing stress at a sharp corner projecting outwards on the cross-section is zero. If the boundary of the cross-section has a sharp re-entrant, the shearing stresses near the corner of such a re-entrant are very severe. Whereas, if the corner is on the vertical symmetrical axis of the section, the shearing stress at 
the corner is zero.

(5) The ultimate strength of a beam under a statical test will not be much reduced by the concentration of shearing stresses at the sharp internal corner on the cross-section. In a fatigue test, however, the effect of such a stress-concentration may, probably, be more serious. It is the author's intention to carry out further experiments on the effect of the sharp corner in a beam by an endurance test.

If the corner of the re-entrant is rounded, the stress at the bottom of it will be reduced. For structural engineers it will be important to investigate how the intensity of the shearing stresses at the rounded corner is related to the radius of the fillet; this is another problem which is left for further investigations.

In conclusion, the author expresses hearty thanks to Professor Suyehiro, for the kindness in giving him many useful suggestions, and to Mr. Sakai, of the Naval Architectural Laboratory in the Tôkyô Imperial University, for the painstaking in preparing the india-rubber models and in assisting him during the experiment.

It will be added here that a part of the experiments has been carried out in the Laboratory mentioned above. 


\section{Appendix I.}

\section{To Find the Flexure Function for Certain Sections.}

I.et us take the longitudinal axis of a beam to be horizontal, and the axis of $z$ along it, and suppose that the axes of $x$ and $y$ are parallel to the priricipal axes of inertia of the cross-section at the centroid, the axis of $x$ being taken vertically downwards.

The flexure function $\chi$ is a function which satisfies the equation

$$
\frac{\partial^{2} \chi}{\partial x^{2}}+\frac{\partial^{2} \chi}{\partial y^{2}}=0^{(1)}
$$

at all points of the cross-section, and the condition

$$
\frac{\partial \chi}{\partial \nu}=-\left\{\frac{1}{2} \sigma x^{2}+\left(\mathrm{I}-\frac{1}{2} \sigma\right) y^{2}\right\} \cos (x, \nu)-(2+\sigma) x y \cos (y, \nu)
$$

at all points of the bounding curve.

When we take the axis of $y$ vertically downwards, the flexure function $\chi^{\prime}$ must satisfy the boundary condition

$$
\frac{\partial \chi^{\prime}}{\partial \nu}=-(2+\sigma) x y \cos (x, \nu)-\left\{\left(1-\frac{1}{2} \sigma\right) x^{2}+\frac{1}{2} \sigma y^{2}\right\} \cos \left(y^{\prime}, \nu\right)
$$

the differential equation being of the same form as the equation (I).

1. Confocal Ellipses, the Major Axis of which is Vertical.- 'Take the major axis of the ellipse as the axis of $x$ and the minor axis as the axis of $y$, and draw the axis of $x$ vertically downwards. We introduce the curvilinear orthogonal co-ordinates $\xi$, $\eta$ given by the equations

$$
x=c \cosh \xi \cos \eta, \quad y=c \sinh \xi \sin \eta,
$$

(I) See any books on the Theory of Elasticity, for instance, Iove, Mathematical Theory of Elasticity. 
and take $\xi_{0}$ and $\xi_{1}$ to be the values of $\xi$ which correspond with the outer and inner boundaries respectively.

The element $d \nu$ of the normal to the curve of the family $\xi$ is

$$
d \nu=\frac{d \xi}{l_{1}}
$$

and the direction cosines of the normal $\nu$ to the $\xi$ curve are

$$
\cos (x, \nu)=\frac{\mathrm{I}}{l_{1}} \frac{\partial \xi}{\partial x}, \quad \cos (y, \nu)=\frac{\mathrm{I}}{l_{1}} \frac{\partial \xi}{\partial y},
$$

where

$$
l_{1}^{2}=\left(\frac{\partial \xi}{\partial x}\right)^{2}+\left(\frac{\partial \xi}{\partial y}\right)^{2}
$$

Therefore, the boundary condition (2) becomes

$$
\begin{aligned}
\frac{\partial \chi}{\partial \xi}= & c^{3} \cos \eta\left\{\left(\frac{1}{16}-\frac{1}{4} \sigma\right) \sinh \xi-\left(\frac{3}{16}+\frac{1}{8} \sigma\right) \sinh 3 \xi\right\} \\
& -c^{33} \cos 3 \eta\left\{\left(\frac{1}{16}-\frac{1}{8} \sigma\right) \sinh \xi-\frac{3}{16} \sinh 3 \xi\right\} .
\end{aligned}
$$

Hence we must have

$\chi=c^{3} \cos \eta\left[\left(\frac{1}{4}-\frac{1}{8} \sigma\right) \cosh \xi-\left(\frac{3}{4}+\frac{1}{2} \sigma\right)\left\{\cosh \xi_{0} \cosh \xi_{1} \cosh \left(\xi_{0}+\xi_{1}\right) \cosh \xi\right.\right.$ $\left.\left.-\sinh \xi_{0} \sinh \xi_{1} \sinh \left(\xi_{0}+\xi_{1}\right) \sinh \xi\right\}\right]$

$$
\begin{aligned}
+c^{3} \cos 3 \eta & {\left[\frac{1}{16} \cosh 3 \xi\right.} \\
& \left.-\left(\frac{1}{16}-\frac{1}{8} \sigma\right) \frac{\sinh \xi_{0} \cosh 3\left(\xi-\xi_{1}\right)-\sinh \xi_{1} \cosh 3\left(\xi_{0}-\xi\right)}{3 \sinh 3\left(\xi_{0}-\xi_{1}\right)}\right] .^{\text {(1) }}
\end{aligned}
$$

2. Confocal Ellipses, the Major Axis of zulich is Horizontal.Take the major axis as the axis of $x$, and the minor axis as the

(1) This expression is given by Love in his "Mathematical Theory of Elasticity," 3rd Edition, p. 342; the coefficient of the second term in the second square brackets given by hia i; " $-\left(\frac{5}{16}-1-\frac{1}{8} \sigma\right) "$, but in order to satisfy the bounday condition it must be " $-\left(\frac{1}{16}-\frac{1}{8} \sigma\right)$ ". 
axis of $y$, and draw the axis of $y$ vertically downwards. Then the boundary condition (3) becomes

$$
\begin{aligned}
\frac{\partial \chi^{\prime}}{\partial \xi}= & -c^{3} \sin \eta\left\{\left(\frac{1}{16}-\frac{1}{4} \sigma\right) \cosh \xi+\left(\frac{3}{16}+\frac{1}{8} \sigma\right) \cosh 3 \xi\right\} \\
& -c^{3} \sin 3 \eta\left\{\left(\frac{1}{16}-\frac{1}{8} \sigma\right) \cosh \xi+\frac{3}{16} \cosh 3 \xi\right\} .
\end{aligned}
$$

Hence we must have

$\chi^{\prime}=-c^{3} \sin \eta\left[\left(\frac{1}{4}-\frac{1}{8} \sigma\right) \sinh \xi+\left(\frac{3}{4}+\frac{1}{2} \sigma\right)\left\{\cosh \xi_{0} \cosh \xi_{1} \sinh \left(\xi_{0}+\xi_{1}\right) \cosh \xi\right.\right.$

$$
\left.\left.-\sinh \xi_{0} \sinh \xi_{1} \cosh \left(\xi_{0}+\xi_{1}\right) \sinh \xi\right\}\right]
$$

$-c^{3} \sin 3 \eta\left[\frac{1}{16} \sinh 3 \xi\right.$

$$
\left.+\left(\frac{1}{16}-\frac{1}{8} \sigma\right) \frac{\cosh \xi_{0} \cosh 3\left(\xi-\xi_{1}\right)-\cosh \xi_{1} \cosh 3\left(\xi_{0}-\xi\right)}{3 \sinh 3\left(\xi_{0}-\xi_{1}\right)}\right]
$$

3. A Sector of a Circlc, whicn its Axis of Symmetry is Virtical.The sector is bounded by $r=a$ and $\theta= \pm \beta$. We take the axis of symmetry for the section to be the axis of $x$ and draw it vertically downwards. (See Fig. 5.)

Let $x^{\prime}, y^{\prime}$ be the rectangular co-ordinates, the axes of which are parallel to the axes of $x$ and $y$, and the origin of which is at the centre of the circle. Let $k$ be the distance of the centroid of the section from the centre of the circle. The differential equation for $\chi$ is still the same as ( 1 ), i.e.,

$$
\frac{\partial^{2} \chi}{\partial x^{\prime 2}}+\frac{\partial^{\prime} \chi}{\partial y^{\prime 2}}=0
$$

and the boundary condition (2) becomes

$$
\begin{aligned}
\frac{\partial \chi}{\partial \nu}=-\left\{\frac{1}{2} \sigma\left(x^{\prime}-k\right)^{2}+\right. & \left.\left(1-\frac{1}{2} \sigma\right) y^{\prime 2}\right\} \cos \left(x^{\prime}, \nu\right) \\
& -(2+\sigma)\left(x^{\prime}-k\right) y^{\prime} \cos \left(y^{\prime}, \nu\right) .
\end{aligned}
$$

The equation (4) expressed in polar co-ordinates is 


$$
\frac{\partial^{2} \chi}{\partial r^{2}}+\frac{\mathrm{I}}{r} \frac{\partial \chi}{\partial r}+\frac{\mathrm{I}}{r^{2}} \frac{\partial^{2} \chi}{\partial \theta^{2}}=0
$$

Let $\nu$ be the outward normal to the boundary of the sector, then we have for the boundary $r=a$, between $\theta=-\beta$ and $\theta=\beta$,

$$
d \nu=d r, \quad \cos \left(x^{\prime}, \nu\right)=\cos \theta, \quad \cos \left(y^{\prime}, \nu\right)=\sin \theta ;
$$

and for the boundary $\theta=\beta$,

$$
d \nu=r d \theta, \quad \cos \left(x^{\prime}, \nu\right)=-\sin \beta, \quad \cos \left(y^{\prime}, \nu\right)=\cos \beta
$$

and for the boundary $\theta=-\beta$,

$$
d \nu=-r d \theta, \quad \cos \left(x^{\prime}, \nu\right)=-\sin \beta, \quad \cos \left(y^{\prime}, \nu\right)=-\cos \beta .
$$

Therefore, from (5), the boundary condition at $r=a$ becomes

$$
\begin{array}{r}
\frac{\partial \chi}{\partial r}=(\mathrm{I}+\sigma) k \alpha-\left\{\left(\frac{3}{4}+\frac{1}{2} \sigma\right) a^{2}+\frac{1}{2} \sigma k^{2}\right\} \cos \theta-k \alpha \cos 2 \theta+\frac{3}{4} a^{2} \cos 3^{\theta}, \\
(\beta>\theta>-\beta) .
\end{array}
$$

The boundary condition at $\theta=\beta$ becomes

$$
\begin{aligned}
\frac{\partial \chi}{\partial \theta}=\frac{1}{2} \sigma k r \sin \beta+h r^{2} \sin 2 \beta+\left\{\left(\frac{1}{4}-\frac{1}{2} \sigma\right) \sin \beta-\frac{3}{4} \sin 3 \beta\right\} r, & \\
& (a>r>0) .
\end{aligned}
$$

And the boundary condition at $\theta=-\beta$ becomes

$$
\begin{aligned}
\frac{\partial \gamma}{\partial \theta}=-\frac{1}{2} \sigma k^{2} r \sin \beta-k r^{2} \sin 2 \beta-\left\{\left(\frac{1}{4}-\frac{1}{2} \sigma\right) \sin \beta-\frac{3}{4} \sin 3 \beta\right\} r^{3} & \\
& (a>r>0) .
\end{aligned}
$$

Now, introduce a new function $\chi_{1}$ given by the equation

$$
\chi_{1}=\chi+\frac{1}{2} \sigma k^{2} r \cos \theta+\frac{1}{2} k r^{2} \cos 2 \theta+\left\{\left(\frac{1}{4}-\frac{1}{2} \sigma\right) \frac{\sin \beta}{3 \sin 3 \beta}-\frac{1}{4}\right\} \gamma^{2} \cos 3^{\theta}
$$

Then, $\partial \chi_{1} / \partial \theta$ vanishes at $\theta= \pm \beta$, and the condition at $r=a$ becomes 


$$
\frac{\partial \chi_{1}}{\partial r}=(1+\sigma) k \alpha-\left(\frac{3}{4}+\frac{1}{2} \sigma\right) a^{2} \cos \theta+\left(\frac{1}{4}-\frac{1}{2} \sigma\right) a^{2} \frac{\sin \beta}{\sin 3 \beta} \cos 3^{(\theta)}
$$

$$
(\beta>\theta>-\beta)
$$

Evidently the function $\chi_{1}$ satisfies the equation

$$
\frac{\partial^{2} \chi_{1}}{\partial r^{2}}+\frac{I}{r} \frac{\partial \chi_{1}}{\partial r}+\frac{I}{r^{2}} \frac{\partial^{2} \chi_{1}}{\partial \theta^{2}}=0
$$

In finding the function $\chi$ from the differential equation and the boundary condition, the additive constant in the expression for $\chi$ should be so chosen that $\chi$ vanishes at the origin. Therefore, if we take the origin at the centroid of the section at the fixed end of the beam, and suppose that the origin is fixed, the constant $\gamma^{\prime}$ in the following expression of the displacement component must be zero:-

$$
w=\tau \phi-\frac{W}{E I}\left[x\left(l z-\frac{1}{2} z^{2}\right)+\chi+x y^{2}\right]-\beta x+\alpha y+\gamma^{\prime},
$$

where $\tau$ is the twist, and $\phi$ the torsion function. The additive constant in the expression for $\phi$ shall be so chosen that this function vanishes at the origin. In the present case we take the origin of the polar co-ordinates at the centre of the circle bounding the sector, instead of the centroid of the section. We may, however, still so choose the additive constant in the expression for $\chi$ that this function vanishes at the origin of the polar co-ordinates. Needless to say, in this case we must give a proper value to $\gamma^{\prime}$ in the expression for $w$, to keep the centroid of the section at the fix $d$ end of the beam fixed.

Accordingly the conditions become

$$
\begin{aligned}
\chi_{1}=0, & \text { at } r=0, & & (\beta>\theta>-\beta), \\
\frac{\partial \chi_{1}}{\partial \theta}=0, & \text { at } \theta= \pm \beta, & & (\alpha>r>0),
\end{aligned}
$$




$$
\frac{\partial \chi_{1}}{\partial r}=f(\theta), \quad \text { at } r=\alpha, \quad(\beta>\theta>-\beta)
$$

where

$$
f(\theta)=(\mathrm{I}+\sigma) k a-\left(\frac{3}{4}+\frac{1}{2} \sigma\right) a^{2} \cos \theta+\left(\frac{1}{4}-\frac{1}{2} \sigma\right) a^{2} \frac{\sin \beta}{\sin 3 \beta} \cos 3^{\theta} .
$$

Particular solutions of the equation (8) are

$$
\begin{array}{ll}
\chi_{1}=r^{\alpha} \cos \alpha \theta, & \chi_{1}=r^{x} \sin \alpha \theta, \\
\chi_{1}=r^{-\alpha} \cos \alpha \theta, & \chi_{1}=r^{-\alpha} \sin \alpha \theta .
\end{array}
$$

From the conditions (9) and (IO), the solution of the equation (8) should be of the type

$$
\chi_{1}=r^{n \pi / \beta} \cos \frac{n \pi \theta}{\beta}
$$

or

$$
\chi_{1}=\gamma^{(2 n+1) \pi / 2 \beta} \sin \frac{(2 n+1) \pi \theta}{2 \beta}
$$

where $n$ is a positive integer including zero. If we expand the function $f(\theta)$ given by (12) in a Fourier's cosine series between the values $\theta=-\beta$ and $\theta=\beta$, then the first term, which is in general constant in the cosine development, vanishes, and we have

$$
f(\theta)=\sum_{n=1}^{\infty} A_{n} \cos \frac{n \pi \theta}{\beta}
$$

where

$$
A_{n}=(-\mathrm{I})^{n} \frac{4 a^{2} \beta \sin \beta\left\{n^{2} \pi^{2} \sigma-3(\mathrm{I}+\sigma) \beta^{2}\right\}}{\left(n^{2} \pi^{2}-\beta^{2}\right)\left(n^{2} \pi^{2}-3^{2} \beta^{2}\right)} .
$$

Now multiply the particular solution

$$
\chi_{1}=r^{n \pi / \beta} \cos \frac{n \pi t}{\beta}
$$


by $\frac{\beta A_{n}}{n \pi a^{n \pi / \beta-1}}$, then we have

$$
\chi_{1}=\frac{\beta A_{22}}{n \pi \alpha^{n \pi / \beta-1}} \gamma^{n \pi / \beta} \cos \frac{n \pi \theta}{\beta},
$$

which is still a solution of the equation (8). Summing this between the limits $n=\mathrm{I}$ and $n=\infty$, we have

$$
\chi_{1}=\frac{\beta}{\pi} \sum_{n=1}^{\infty} \frac{A_{n}}{n a^{n 2 \pi / \beta-1}} r^{n \pi / \beta} \cos \frac{n \pi \theta}{\beta},
$$

which satisfies also the equation (8) and the conditions (9) and (10). Differentiating this with respect to $r$, and suistituting $r=a$, we get

$$
\frac{\partial \chi_{1}}{\partial r}=\sum_{n=1}^{\infty} A_{n} \cos \frac{n \pi \theta}{\beta}
$$

which is identical to the expression (13) of the function $f(\theta)$. Therefore, the above form of $\chi_{1}$ given by (14) satisfies also the condition (II), and is the solution of the equation (8). Hence, by means of (7), and slightly modifying the forms of the coefficients, we have

$$
\begin{aligned}
\chi=-\frac{1}{2} \sigma k^{2} r \cos \theta-\frac{1}{2} k r^{2} \cos 2 \theta & -\left\{\left(\frac{1}{4}-\frac{1}{2} \sigma\right) \frac{\sin \beta}{3 \sin 3 \beta}-\frac{1}{4}\right\} r^{3} \cos 3^{\theta} \\
& +\frac{4 \alpha^{3} \beta^{2} \sin \beta}{\pi} \sum_{n=1}^{\infty} B_{n}\left(\frac{r}{a}\right)^{n \pi / \beta} \cos \frac{n \pi \theta}{\beta},
\end{aligned}
$$

where

$$
B_{n}=\frac{(-\mathrm{I})^{n}}{n} \frac{n^{2} \pi^{2} \sigma-3(\mathrm{I}+\sigma) \beta^{2}}{\left(n n^{2} \pi^{2}-\beta^{2}\right)\left(n n^{2} \pi^{2}-3^{2} \beta^{2}\right)}
$$

4. A Sector of a Circle, when its Axis of Symmitry is Horizontal.The sector is supposed to be bounded by $r=a$ and $\theta= \pm \beta$. We take the axis of symmetry of the section to be the axis of $x$, and draw the axis of $y$ vertically downwards. 
Referring to polar co-ordinates, the differential equation of the flexure function $\chi^{\prime}$ is

$$
\frac{\partial^{2} \chi^{\prime}}{\partial r^{2}}+\frac{1}{r} \frac{\partial \chi^{\prime}}{\partial r}+\frac{1}{r^{2}} \frac{\partial^{2} \chi^{\prime}}{\partial \theta^{2}}=0
$$

Transforming the origin of the co-ordinates to the centre of the circle, and expressing by polar co-ordinates, the boundary condition (3) becomes

$$
\begin{array}{r}
\frac{\partial \chi^{\prime}}{\partial \gamma}=-\left\{\left(\frac{3}{4}+\frac{1}{2} \sigma\right) a^{2}+\left(\mathrm{I}-\frac{1}{2} \sigma\right) k^{2}\right\} \sin \theta+2 k \alpha \sin 2 \theta-\frac{3}{4} \alpha^{2} \sin 3^{\theta}, \\
\text { at } r=a, \quad(\beta>\theta>-\beta),
\end{array}
$$

and

$$
\begin{aligned}
\frac{\partial \chi^{\prime}}{\partial \theta}= & -\left(\mathrm{I}-\frac{1}{2} \sigma\right) k^{2} r \cos \beta-(\sigma-2 \cos 2 \beta) k r^{2} \\
& -\left\{\left(\frac{1}{4}-\frac{1}{2} \sigma\right) \cos \beta+\frac{3}{4} \cos 3 \beta\right\} r^{3}, \quad \text { at } \theta= \pm \beta, \quad(\alpha>r>0) .
\end{aligned}
$$

Introduce a new function $\chi^{\prime \prime}$ given by the equation

$$
\begin{aligned}
& \chi^{\prime \prime}=\chi^{\prime}+\left(\mathrm{I}-\frac{1}{2} \sigma\right) k^{2} r \sin \theta+\left(\frac{1}{2} \sigma \frac{\mathrm{I}}{\cos 2 \beta}-\mathrm{I}\right) k r^{2} \sin 2 \theta \\
& +\left\{\left(\frac{1}{4}-\frac{1}{2} \sigma\right) \frac{\cos \beta}{3 \cos 3 \beta}+\frac{1}{4}\right\} r^{3} \sin 3 \theta \text {. }
\end{aligned}
$$

Then, $\partial \gamma^{\prime \prime} / \partial \theta$ vanishes at $\theta= \pm \beta$, and the condition at $r=a$ becomes

$$
\begin{aligned}
\frac{\partial \chi^{\prime \prime}}{\partial r}= & -\left(\frac{3}{4}+\frac{1}{2} \sigma\right) a^{2} \sin \theta+\sigma k a \frac{\mathrm{I}}{\cos 2 \beta} \sin 2 \theta \\
& +\left(\frac{1}{4}-\frac{1}{2} \sigma\right) a^{2} \frac{\cos \beta}{\cos 3 \beta} \sin 3^{\theta,} \quad(\beta>\theta>-\beta) .
\end{aligned}
$$

Evidently the function $\chi^{\prime \prime}$ satisfies the equation

$$
\frac{\partial^{2} \chi^{\prime \prime}}{\partial r^{2}}+\frac{1}{r} \frac{\partial \chi^{\prime \prime}}{\partial r}+\frac{1}{r^{2}} \frac{\partial^{2} \chi^{\prime \prime}}{\partial \theta^{2}}=0
$$


In solving the equation (15) we may so choose the additive constant that $\chi^{\prime}$ vanishes at $r=0$. Hence the conditions become

$$
\begin{aligned}
& \chi^{\prime \prime}=0, \quad \text { at } r=0, \quad(\beta>\theta>-\beta), \\
& \frac{\partial \chi^{\prime \prime}}{\partial \theta}=0, \quad \text { at } \theta= \pm \beta, \quad(a>r>0), \\
& \frac{\partial \chi^{\prime \prime}}{\partial \gamma}=\psi(\theta), \quad \text { at } r=a, \quad(\beta>\theta>-\beta),
\end{aligned}
$$

where

$$
\begin{aligned}
\varphi(\theta)= & -\left(\frac{3}{4}+\frac{1}{2} \sigma\right) a^{2} \sin \theta+\sigma k \alpha \frac{\mathrm{I}}{\cos 2 \beta} \sin 2 \theta \\
& +\left(\frac{1}{4}-\frac{1}{2} \sigma\right) a^{2} \frac{\cos \beta}{\cos 3 \beta} \sin 3 \theta . \ldots \ldots \ldots \ldots
\end{aligned}
$$

Particular solutions of the equation (I7) are

$$
\begin{array}{ll}
\chi^{\prime \prime}=r^{\alpha} \cos \alpha \theta, & \chi^{\prime \prime}=r^{\alpha} \sin \alpha \theta, \\
\chi^{\prime \prime}=r^{-\alpha} \cos \alpha \theta, & \chi^{\prime \prime}=r^{-\alpha} \sin \alpha \theta .
\end{array}
$$

(18) and (19) suggest that the solution should be one of the types

$$
\chi^{\prime \prime}=r^{n \pi / \beta} \cos \frac{n \pi \theta}{\beta},
$$

and

$$
\chi^{\prime \prime}=2^{(2 n+1) \pi / 2 \beta} \sin \frac{(2 n+1) \pi \theta}{2 \beta},
$$

where $n$ is a positive integer including zero. In comparing with (20), it will be seen that the type of the solution should be of the second of the above two types.

If we assume that, when $\beta>\theta>-\beta$, the function $\phi(\theta)$ given by (2I) can be expanded in a series of the form

$$
\zeta^{\prime}(\theta)=\sum_{n=0}^{\infty} A_{2 n+1} \sin \frac{(2 n+\mathrm{I}) \pi \theta}{2 \beta},
$$


we may determine the coefficients $A_{2 n+1}$ by multiplying both members of this equation by $\sin \{(2 n+1) \pi \theta / 2 \beta\}$, and integrating both members with respect to $\theta$ between the extreme values $-\beta$ and $\beta$. 'Thus we have

$$
\begin{aligned}
A_{2 n+1}=(-1)^{n+1} 2^{3} a^{2} \beta\left\{\frac{\left(\frac{3}{4}+\frac{1}{2} \sigma\right) \cos \beta}{(2 n+1)^{2} \pi^{2}-2^{2} \beta^{2}}\right. & -\frac{2 \sigma k / \alpha}{(2 n+1)^{2} \pi^{2}-2^{2} \cdot 2^{2} \beta^{2}} \\
& \left.-\frac{3\left(\frac{1}{4}-\frac{1}{2} \sigma\right) \cos \beta}{(2 n+1)^{2} \pi^{2}-2^{2} \cdot 3^{2} \beta^{2}}\right\} .
\end{aligned}
$$

We cannot at once conclude that this result is proved by Fourier's theorem, because a Fourier's sine series of multiples of $\pi \theta / 2 \beta$ represents a function in an interval given by $2 \beta>\theta>-2 \beta$, and the value of the function to be expanded is given only in the interval $\beta>\theta>-\beta$. If the Fourier's sine series contains uneven multiples of $\pi \theta / 2 \beta$ only, the sign of every term of it is unchanged when we put $2 \beta-\theta$ in place of $\theta$; it follows that, if the series (22) is a Fourier's series of which the sum is equal to $(2 \mathrm{I})$ when $\beta>\theta>0$, the sum of the series when $2 \beta>\theta>\beta$ is

$$
\begin{aligned}
& -\left(\frac{3}{4}+\frac{1}{2} \sigma\right) a^{2} \sin (2 \beta-\theta)+\sigma k a \frac{1}{\cos 2 \beta} \sin 2(2 \beta-\theta) \\
& +\left(\frac{1}{4}-\frac{1}{2} \sigma\right) a^{2} \frac{\cos \beta}{\cos 3 \beta} \sin 3(2 \beta-\theta) . \quad \ldots \ldots \ldots \ldots \ldots \ldots \ldots
\end{aligned}
$$

Now we may show that the Fourier's series for an odd function of $\theta$, which has the value given by $(2 \mathrm{I})$ when $\beta>\theta>0$, and the value given by $(23)$ when $2 \beta>\theta>\beta$, is in fact the series (22). Hence we may conclude that, when $\beta>\theta>-\beta$, the function $\psi(\theta)$ given by (2I) can be expanded in a series (22), the terms of which contain sines of odd multiples of $\pi \theta / 2 \beta$ only. ${ }^{(1)}$

(x) A similar proof that, when $b>y>-b$, an even function of $y$ can be expanded in a Fourier's cosine series of uneven multiples of $\pi y / 2 b$ only, is given in Love, Mathematical Theory of Elasticity, 3rd edition, p. 323. 
Shearing Stresses in Beams of Certain Cross-Sections.

Now multiplying the particular solution

$$
\chi^{\prime \prime}=\gamma^{(2 n+1) \pi 2 \beta} \sin \frac{(2 n+\mathrm{I}) \pi \theta}{2 \beta}
$$

by $\frac{2 \beta A_{2 n+1}}{(2 n+\mathrm{I}) \pi a^{(2 n+1) \pi / 2 \beta-1}}$, then we have

$$
\chi^{\prime \prime}=\frac{2 \beta A_{2 n+1}}{(2 n+\mathrm{I}) \pi \alpha^{(2 n+1) \pi / 2 \beta-1}} r^{(2 n+1) \pi / 2 \beta} \sin \frac{(2 n+\mathrm{I}) \pi \theta}{2 \beta}
$$

which is still a solution of ( 17$)$. Summing this between the limits $n=0$ and $n=\infty$, we have

$$
\chi^{\prime \prime}=\frac{2 \beta}{\pi} \sum_{n=0}^{\infty} \frac{A_{2 n+1}}{(2 n+1) d^{(2 n+1) \pi / 2 \beta-1}} \gamma^{(2, n+1) \pi / 2 \beta} \sin \frac{(2 n+1) \pi \theta}{2 \beta}
$$

which satisfies also the equation ( 17 ) and the conditions (I8) and (19). Differentiating this with respect to $r$, and making $r=\alpha$, we get

$$
\frac{\partial \chi^{\prime \prime}}{\partial r}=\sum_{n=0}^{\infty} \Lambda_{2 n+1} \sin \frac{(2 n+1) \pi \theta}{2 \beta}
$$

which is identical to the expression (22) for the function $\phi(\theta)$. Therefore, the above form of $\chi^{\prime \prime}$ given by (24) satisfies also the condition (20), and is the solution of the equation ( 17 ). Hence, by means of (16), and slightly modifying the forms of the coefficients, we have

$$
\begin{aligned}
\chi^{\prime}= & -\left(\mathrm{I}-\frac{1}{2} \sigma\right) k^{2} r \sin \theta-\left(\frac{1}{2} \sigma \frac{\mathrm{I}}{\cos 2 \beta}-\mathrm{I}\right) k r^{2} \sin 2 \theta \\
& -\left\{\left(\frac{1}{4}-\frac{1}{2} \sigma\right) \frac{\cos \beta}{3 \cos 3 \beta}+\frac{1}{4}\right\} r^{3} \sin 3^{\theta} \\
& +\frac{\mathrm{I} 6 \alpha^{3} \beta^{2}}{\pi} \sum_{n=0}^{\infty} B_{a_{n+1}}\left(\frac{r}{a}\right)^{(2, n+1) \pi / 2 \beta} \sin \frac{(2 n+\mathrm{I}) \pi \theta}{2 \beta}
\end{aligned}
$$


where

$$
\begin{aligned}
B_{2: i+1}=\frac{(-1)^{n+1}}{2 n+I}\left\{\frac{\left(\frac{3}{4}+\frac{1}{2} \sigma\right) \cos \beta}{(2 n+I)^{2} \pi^{2}-2^{2} \beta^{2}}-\frac{2 \sigma k / \alpha}{(2 n+I)^{2} \pi^{2}-2^{2} \cdot 2^{2} \beta^{2}}\right. & \\
& \left.-\frac{3\left(\frac{1}{4}-\frac{1}{2} \sigma\right) \cos \beta}{(2 n+1)^{2} \pi^{2}-2^{2} \cdot 3^{2} \beta^{2}}\right\} .
\end{aligned}
$$

\section{Appendix II.}

\section{Shearing Stresses in Beams of Certain Simple Cross-Sections.}

I. A Circular Cylindrical Beam.- The flexure function for a circular section is

$$
\chi=-\left(\frac{3}{4}+\frac{1}{2} \sigma\right) a^{2} x+\frac{1}{4}\left(x^{3}-3 x y^{2}\right),{ }^{(1)}
$$

where $a=$ the radius of the section. From this we have

$$
\begin{aligned}
& X_{z}=-\frac{W}{2(\mathrm{I}+\sigma) I}\left\{-\left(\frac{3}{4}+\frac{1}{2} \sigma\right) a^{2}+\left(\frac{3}{4}+\frac{1}{2} \sigma\right) x^{2}+\left(\frac{1}{4}-\frac{1}{2} \sigma\right) y^{2}\right\}, \\
& V_{z}=-\frac{W}{2(\mathrm{I}+\sigma) I}\left(\frac{1}{2}+\sigma\right) x y .
\end{aligned}
$$

On the horizontal centre line, we have

$$
\begin{aligned}
& X_{z}=\frac{W}{2(1+\sigma) I}\left\{\left(\frac{3}{4}+\frac{1}{2} \sigma\right) a^{2}-\left(\frac{1}{4}-\frac{1}{2} \sigma\right) y^{2}\right\}, \\
& Y_{z}=\mathrm{O},
\end{aligned}
$$

the distribution of which is shown in Fig. 4.

2. A Hollow Circular Cylindrical Beam.- The shearing stress components on the cross-section of a hollow circular cylindrical beam are

(1) Love, Mathematical Theory of Elasticity, 3rd edition, p. 340. 


$$
\begin{aligned}
X_{z}=-\frac{W}{2(\mathrm{I}+\sigma) I}[ & -\left(\frac{3}{4}+\frac{1}{2} \sigma\right)\left\{\left(a_{0}{ }^{2}+a_{1}^{2}\right)-\frac{a_{0}^{2} a_{1}^{2}\left(\cos ^{2} \theta-\sin ^{2} \theta\right)}{r^{2}}\right\} \\
& \left.+\left(\frac{3}{4}+\frac{1}{2} \sigma\right) r^{2} \cos ^{2} \theta+\left(\frac{1}{4}-\frac{1}{2} \sigma\right) r^{2} \sin ^{2} \theta\right]^{(1)} \\
Y_{z}=-\frac{W}{2(\mathrm{I}+\sigma) I} & {\left[\left(\frac{3}{4}+\frac{1}{2} \sigma\right) \frac{2 a_{0}^{2} a_{1}^{2}}{r^{2}}+\left(\frac{1}{2}+\sigma\right) r^{2}\right] \cos \theta \sin \theta }
\end{aligned}
$$

where $\alpha_{0}=$ the outer radius of the section,

$\alpha_{1}=$ the inner radius of the section.

On the horizontal centre line, we have

$$
\begin{aligned}
& X_{z}=\frac{W}{2(\mathrm{I}+\sigma) I}\left[\left(\frac{3}{4}+\frac{1}{2} \sigma\right)\left\{\left(a_{0}{ }^{2}+\alpha_{1}{ }^{2}\right)+\frac{a_{0}{ }^{2} a_{1}{ }^{2}}{r^{2}}\right\}-\left(\frac{1}{4}-\frac{1}{2} \sigma\right) r^{2}\right], \\
& Y_{z}=0 .
\end{aligned}
$$

At the inner edge of the cross-section on the horizontal centre line, we have, substituting $r=a_{1}$ in the above equation,

$$
X_{2}=\frac{W}{2(\mathrm{I}+\sigma) I}\left\{\left(\frac{3}{2}+\sigma\right) a_{0}^{2}+\left(\frac{1}{2}+\sigma\right) a_{1}^{2}\right\}
$$

If the inner diameter of the hollow circular cylindrical beam becomes very small, we have a circular cylindrical beam having a small circular cavity along its longitudinal axis. The shearing stress at the side of the horizontal centre line of the cavity will be, from the above equation,

$$
X_{z}=\frac{(3+2 \sigma) W a_{0}{ }^{2}}{4(1+\sigma) I}
$$

The shearing stress near the centre of a solid circular cylindrical beam obtained from the previous case is

(I) Prof. Suyehiro, "On Shearing Stress in a Ship's Structure," Jour. Soc. Nav. Arch., Tôkyô, Vol. XI. 


$$
X_{z}=\frac{(3+2 \sigma) W a^{2}}{8(\mathrm{I}+\sigma) I}
$$

Therefore, the shearing stress at the side of the horizontal centre line of a very small cavity which is at the centre of a circular beam is twice the shearing stress at the corresponding point of a solid circular beam of the same diamet

The distribution of the shearing stresses on the cross-section of a circular cylindrical beam with a small cirçular cavity at the centre having the diameter of $1 / 27.3^{\text {th }}$ of that of the section, is. shown in Fig. 4. In this, Poisson's ratio is assumed to be $1 / 4$. 


\title{
第 十 九 號
}

\section{大正十五年八月發行}

\section{抄錄}

\section{或る橫斷面を有する二三の壔狀梁內の 剪應力分布に就て}

\author{
所員 工學士 井口常 雄
}

梁の内に起る前應力は「サン・ブナン」の鹳み函数 (Flexure function) 用るて數學的に求めることが出來る。本諭女に於ては二つの同焦點棈

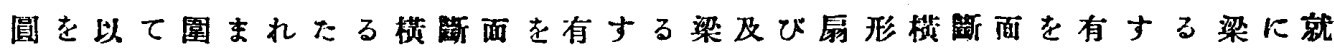

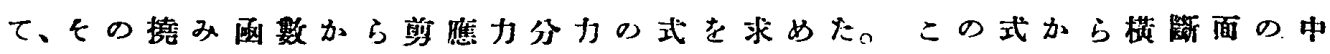

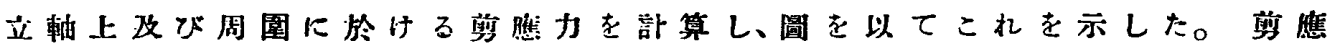
扎をの圖の中立軸上に於ける分布を見ても分る通り、横斷面上の水平 線に沿ひて浹して一栐ではない。工學上では盖㫿力の垂直分力を一水 咋線上に於て一栐であると假定するが、この假定による值は一水作線上

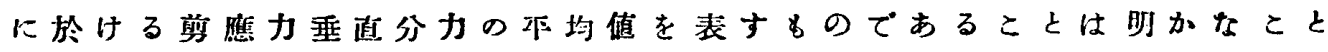
である。

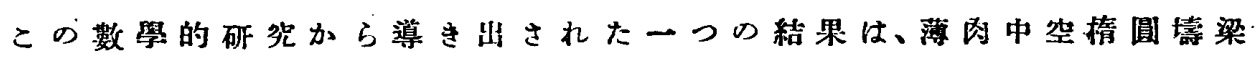

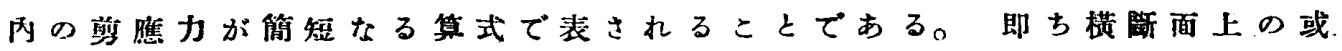
る一點に於ける剪應力は梁の壁の切線方向に缏き。梁の壁の内外雨面に 於て殆ど相等しき值を有し、從つて一點に於ける剪㮣力はその點を過を る厚さ上に於ける剪㫿力の和均值を以て近似的にこれを表すことが出 來るのである。その式は狄に示す通りである:-

$$
q=\frac{\Pi m}{2 t 1}
$$

上式中に於て

$$
\begin{aligned}
& q=\text { 横萿面上の或る一點に於ける盖㮣力。 } \\
& \mathrm{W}=\text { 剪断力、 }
\end{aligned}
$$




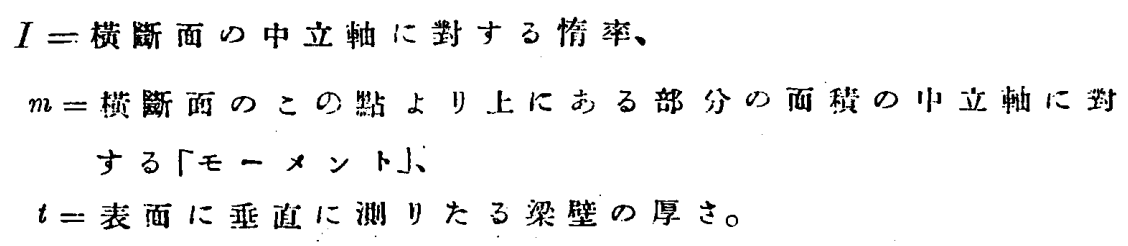

この式は工學上普通に用るられて居るものと绐ど同じ形であるが、tを

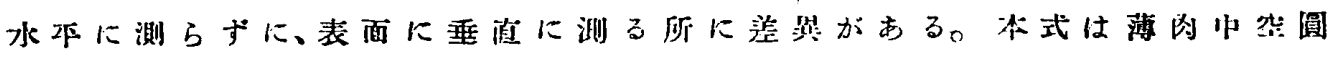

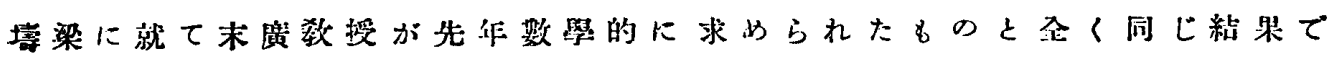
あるが、棈圆形の場合にも同栐であることがこっに證盯せられた。何ほ

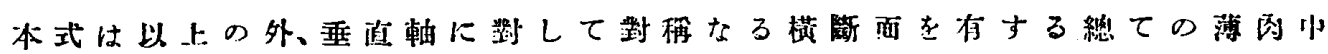
空梁に適用するとと出出來る。

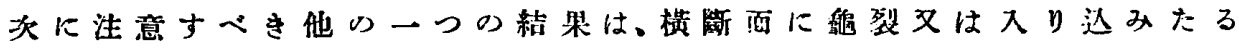

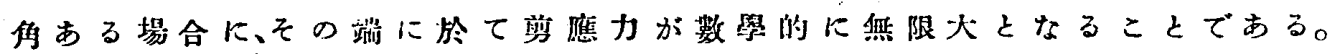

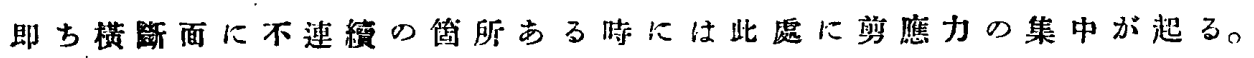

剪䂠力の集中に就ては、賀驗上からもその存在を證朋した。第一の

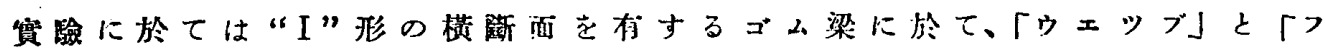

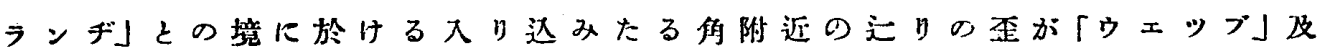
び「フランヂ」の表面上か他の點に於ける歪より大であることを認めた。

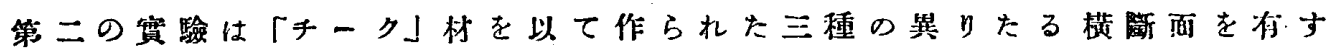

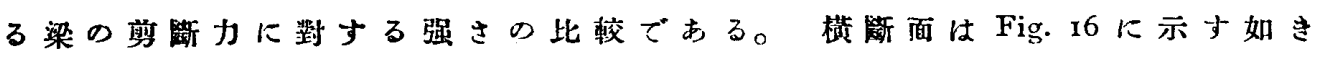

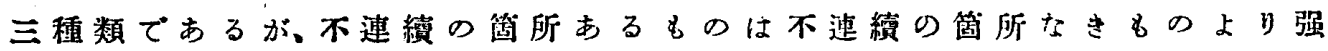

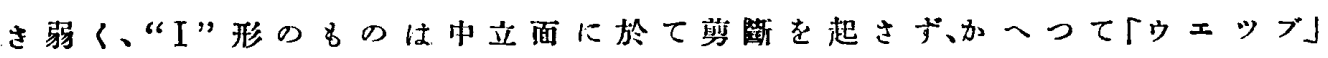

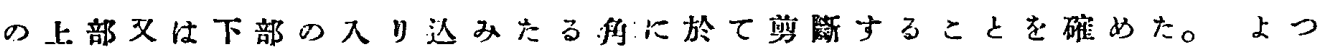

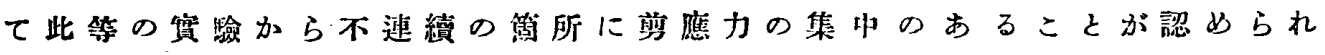
3。

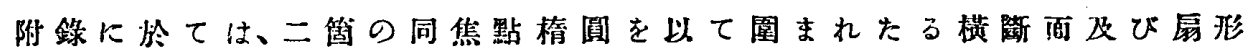

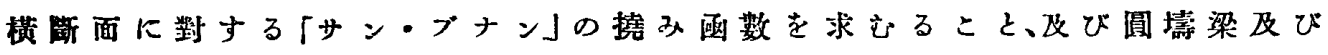

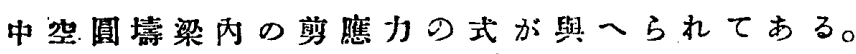


Report No. 19.

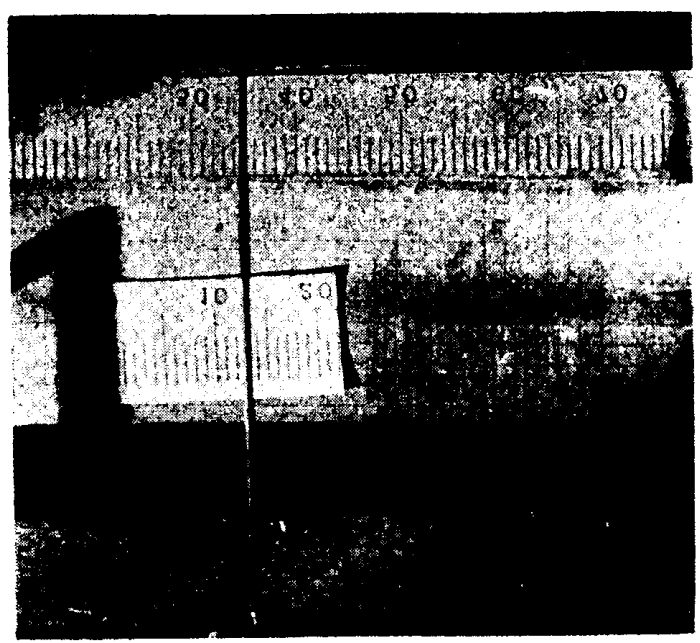

Fig. Io. Initial State of the Surface of the Wel.

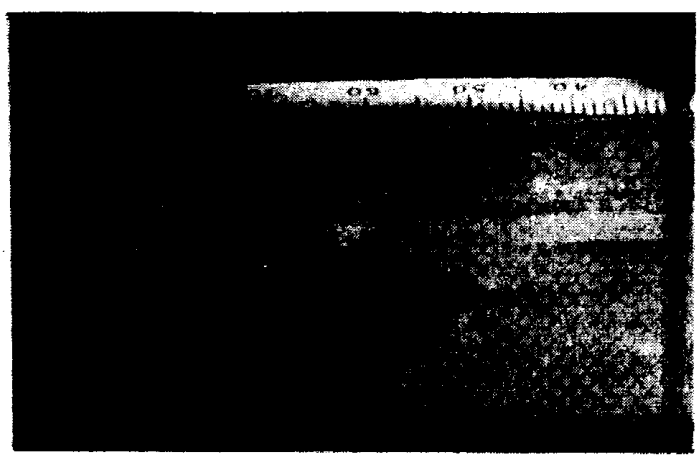

Fig. I2. Initial State of the Inver Surface of the Flange.
(Vol. II.), Pl. 8.

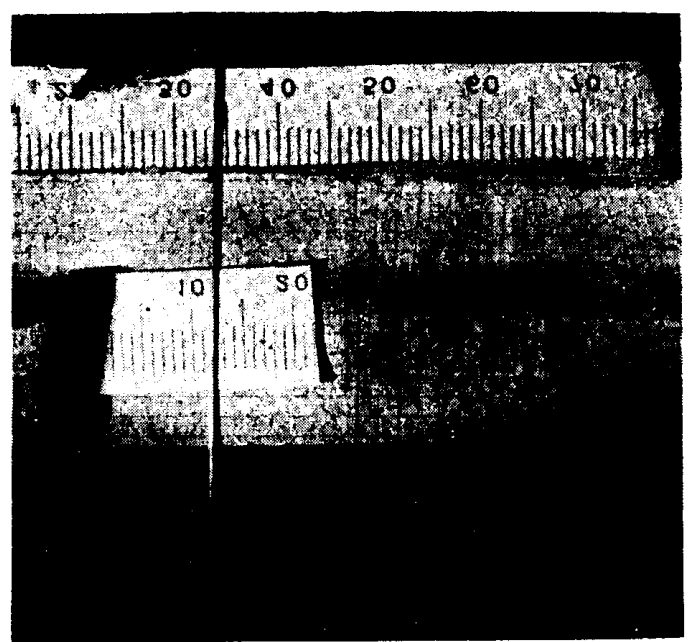

Fig. Ix. S:rained State of the Surfae of the Web.

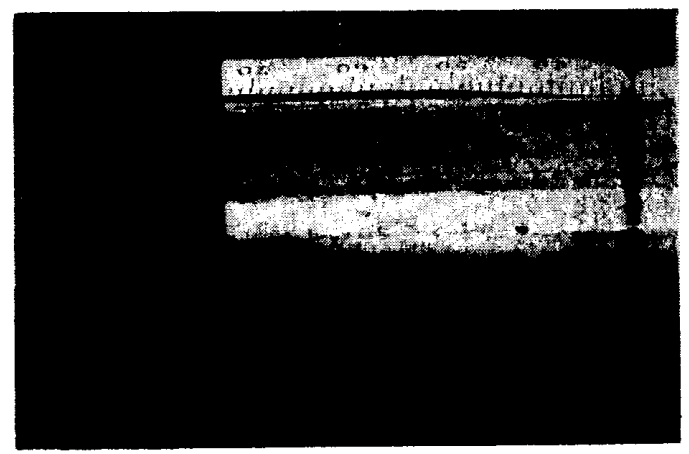

Fig. 13. Strained State of the Inrer Surface of the Flange.

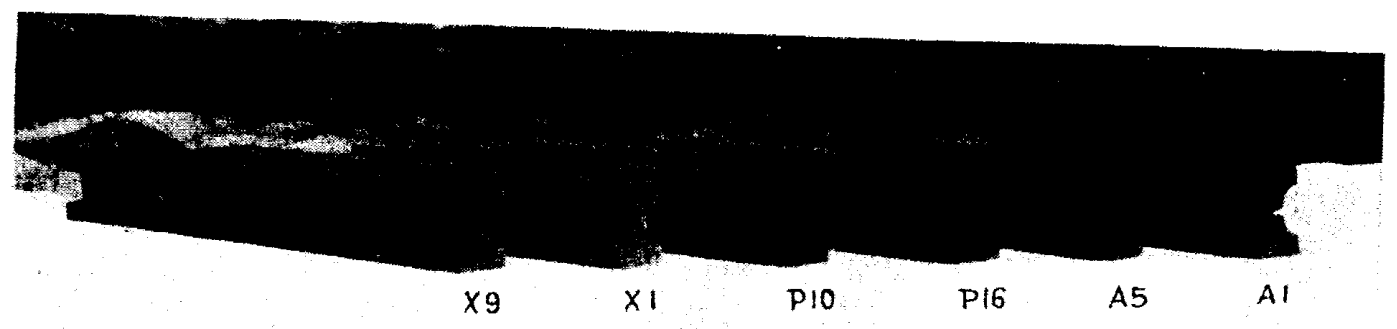

Fig. 18. Shearing liractures of 'Teak Feans. 